\title{
Evaluation of analytical methodologies used to derive vulnerability functions
}

\author{
V. Silva ${ }^{1,2, *, \dagger}$, H. Crowley ${ }^{2}$, H. Varum ${ }^{1}$, R. Pinho ${ }^{3}$ and R. Sousa ${ }^{4}$ \\ ${ }^{1}$ University of Aveiro, Portugal \\ ${ }^{2}$ EUCENTRE, Pavia, Italy \\ ${ }^{3}$ University of Pavia, Italy \\ ${ }^{4}$ ROSE Programme, UME School, IUSS Pavia, Italy
}

\begin{abstract}
SUMMARY
The recognition of fragility and vulnerability functions as a fundamental tool in seismic risk assessment has led to the development of more and more complex and elaborate procedures for their computation. Although these functions have been traditionally produced using observed damage and loss data, more recent studies propose the employment of analytical methodologies as a way to overcome the frequent lack of post-earthquake data. The variation of the structural modelling approach on the estimation of building capacity has been the target of many studies in the past; however, its influence on the resulting vulnerability model for classes of buildings, the impact in loss estimations or propagation of the uncertainty to the seismic risk calculations has so far been the object of limited scrutiny. In this paper, an extensive study of static and dynamic procedures for estimating the nonlinear response of buildings has been carried out to evaluate the impact of the chosen methodology on the resulting capacity, fragility, vulnerability and risk outputs. Moreover, the computational effort and numerical stability provided by each approach have been evaluated and conclusions drawn regarding the optimal balance between accuracy and complexity. Copyright (C) 2013 John Wiley \& Sons, Ltd.
\end{abstract}

Received 4 October 2012; Revised 2 June 2013; Accepted 4 June 2013

KEY WORDS: fragility; vulnerability; analytical methodologies; loss assessment

\section{INTRODUCTION}

Vulnerability functions, a fundamental component in the process of assessing seismic risk, can be defined as the probabilistic distribution of loss ratio conditional on a certain level of ground motion. Fragility functions, defining the probability of exceeding a set of damage states, can be combined with a consequence model, which establishes the relation between physical damage and a percentage of loss, to derive vulnerability functions. Building damage and repair cost data from past earthquakes can be used to derive both of these types of models [1-3]. However, empirical methodologies can have some disadvantages such as the subjectivity in allocating each building to a damage state or the lack of accuracy in the determination of the ground motion affecting the region. Furthermore, there are only a few dozen places in the world where post-earthquake damage and repair cost data has been collected from a number of buildings large enough to permit the development of reliable vulnerability functions. To overcome these limitations, analytical methodologies can be employed in either a single structure that is believed to be representative of a class of buildings, or a set of randomly generated buildings, modelled using structural analysis techniques, and subjected to specific lateral loading patterns or accelerograms [4-7].

\footnotetext{
*Correspondence to: V. Silva, University of Aveiro, Portugal.
}

†E-mail: vitor.silva@eucentre.it 
As discussed by Rossetto and Elnashai [8], there is no unique methodology for the development of fragility functions and therefore, the resulting curves will be conditional on the assumptions and techniques followed within the selected methodology. These discrepancies because of to the different approaches will consequently introduce differences in the risk assessments, even when considering the exact same region, seismicity and types of structures [9]. Despite the existence of various studies that have evaluated the differences in the seismic response of buildings provided by alternative methodologies [10-12], the impact of this epistemic uncertainty in the computation of fragility and vulnerability functions and the estimation of seismic risk has been the subject of less investigation.

The various analytical methodologies for structural assessment can be categorized in two main groups: nonlinear dynamic analysis and nonlinear static analysis, each one having its own strengths and shortcomings. The main advantage in employing nonlinear dynamic analysis is certainly the fact that the actual dynamic phenomenon is reproduced by applying an acceleration time history at the base of the structure, leading in theory to more accurate results. However, the intrinsic modelling complexity (e.g., hysteric response models, equivalent viscous damping) combined with the heavy computational effort, is often impractical, thus favoring the employment of simpler methods, comprising nonlinear static analysis [13]. In this second approach, pushover curves are computed and used to estimate the maximum displacement response experienced by the structure for a given ground motion record. The main drawback of this simplified methodology lies with the assumption that the structural response obtained from horizontal static loading is representative of the one attained in the dynamic analysis.

In this paper, several analytical methodologies are used to derive fragility functions for the same structural typology. A number of static approaches are investigated herein based on conventional and adaptive pushover analyses together with nonlinear static procedures (e.g., capacity spectrum method (CSM) [14], displacement coefficient method (DCM) [15], N2 method [16]), by using hundreds of ground motion records, to derive fragility functions for different levels of ground motion (intensity measure levels). Then, dynamic analysis is used as the baseline method in this sensitivity study, to yield conclusions regarding the relative accuracy of each method. Each set of fragility functions is transformed into vulnerability functions (i.e., probability of loss for a given level of ground motion) by calculating the mean damage ratio (i.e., ratio of cost of repair to cost of replacement) for a number of intensity measure levels. In all methods, hundreds of 2D reinforced concrete bare frames have been simulated using a Monte Carlo approach on the basis of the variability in the material and geometric properties of real buildings. In this study, advantage was taken of the availability of detailed characteristics of reinforced concrete buildings in Turkey assembled by Bal et al. [17].

\section{DESCRIPTION OF THE FRAMEWORK}

For the purposes of this study, a comprehensive probabilistic framework was developed and its architecture is schematically represented in Figure 1.

Within this framework, regardless of the chosen analytical methodology, the process of computing fragility curves always starts with the generation of a population of 2D Reinforced concrete frames through Monte Carlo simulation. Then, the sample of synthetic frames is subjected to a set of ground motion records through the use of either static or dynamic analysis. In the static analysis, a pushover curve is generated for each frame and transformed into the capacity curve of the equivalent SDOF system. Then, for each capacity curve, the nonlinear target displacement for a set of ground motion records is estimated by using a nonlinear static procedure (NSP). The target displacement for each ground motion record is employed to allocate each frame in a damage state, according to limit state criteria. In the dynamic analysis, each frame is assigned a global damage state on the basis of the maximum roof displacement registered during the nonlinear time history analysis, which is again compared with the limit state displacements. Thus, for each record, the number of frames in each damage state will be obtained. This distribution of buildings in each damage state can be organized in a damage probability matrix, with a number of columns equal to 


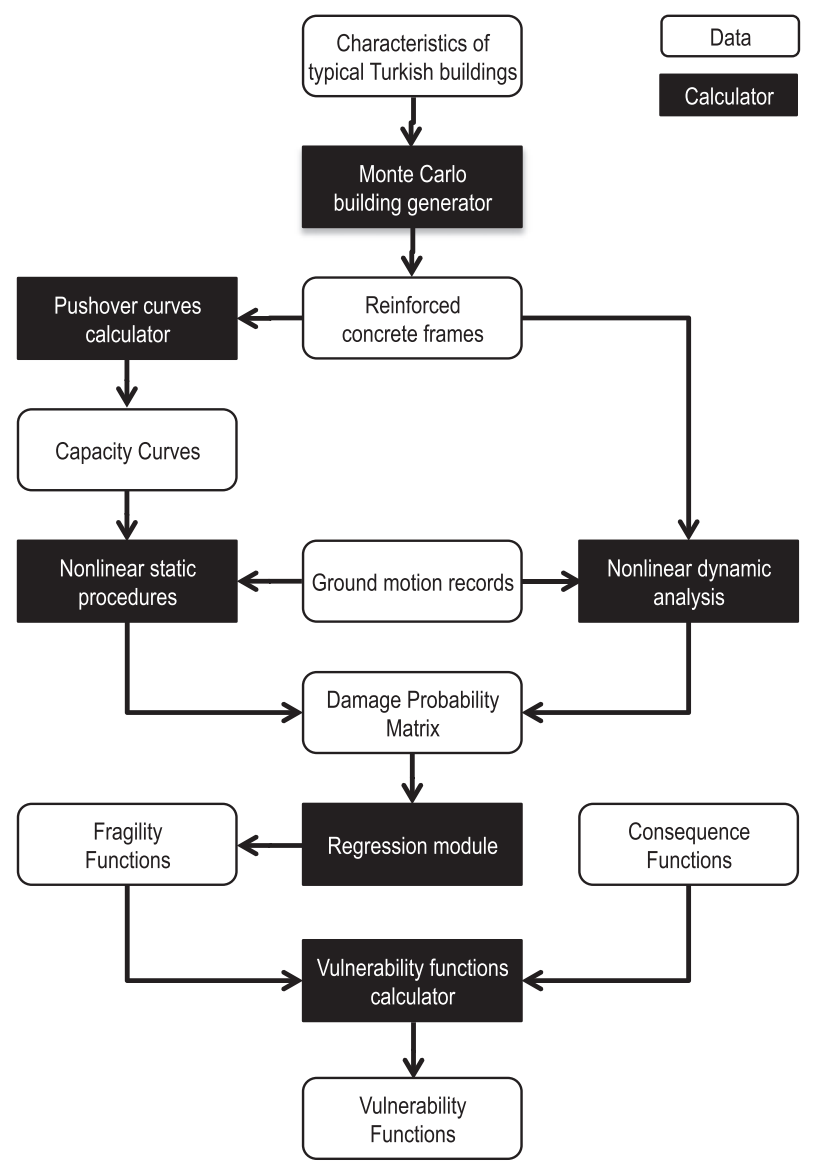

Figure 1. Scheme of the developed framework.

the number of ground motion records and a number of rows equal to the number of damage states. Regression analysis (mean least squares method) can then be applied to this data to fit a lognormal curve for each limit state (leading to a fragility curve). All the fragility functions were derived using spectral acceleration for the fundamental period, $\mathrm{Sa}\left(\mathrm{T}_{\mathrm{el}}\right)$, which is an intensity measure type capable of providing a good correlation to building damage [18, 19]. Each set of fragility functions have been combined with a consequence model (relating physical damage to percentage of loss) to produce a vulnerability model.

Regarding the damage criterion adopted in the present study, as discussed in Akkar et al. [6], there are several options regarding criteria to allocate buildings to a damage state. These may include the maximum roof displacement, interstorey drift ratio, steel or concrete strain level, maximum base shear, and so on. Each option will naturally lead to different damage distributions, and consequently, different fragility functions. The influence of these criteria has been discussed in previous studies [20] and will not be further investigated in this work. In this study, the maximum roof displacement has been used to identify the threshold between each damage state as described later:

- Limit state 1: roof displacement when $75 \%$ of the maximum base shear capacity is achieved;

- Limit state 2: roof displacement when the maximum base shear capacity is achieved;

- Limit state 3: roof displacement when the base shear capacity decreases $20 \%$.

Until limit state 1, the structure can be assumed to have none to slight damage; between limit state 1 and 2 the structure is presumed to have moderate damage; extensive damage occurs between limit state 2 up to 3 ; and collapse is achieved when limit state 3 is exceeded. It is recognized that the maximum roof displacement is a very simplified criterion to allocate buildings to a damage state, and that the findings from this study should be tested against results using other limit state criteria. The influence 
of this aspect in the development of fragility/vulnerability functions is the subject of another ongoing investigation by the authors.

\subsection{Generation of synthetic RC frames}

In all methods applied herein, hundreds of 2D reinforced concrete bare frames have been simulated using a Monte Carlo approach on the basis of the variability in the material and geometric properties of real typical Turkish buildings gathered by Bal et al. [17]. In the latter work, hundreds of drawings from buildings located in the Marmara region were used to measure several geometrical properties. Then, for each property, the statistical parameters from the probabilistic distribution that provided the best fit were calculated. With regards to the steel and concrete material properties, Bal et al. [17] took advantage of some existing studies from Akyuz and Uyan [21] and Bal and Yildiz [22].

To maintain the computational effort at a reasonable level, a single type of frame was considered, with 4 stories and 3 bays, as demonstrated in Figure 2.

A MATLAB [23] script was developed to individually produce and design each frame. In a first phase, controlled Monte Carlo simulation is used to randomly sample several parameters on the basis of the probabilistic distributions proposed by Bal et al. [17]. These parameters and the associated statistical models are presented in Table I.

Each parameter was sampled independently (without correlation), although for the bay lengths within a given frame, a correlation factor of 0.7 was used, to avoid the generation of highly irregular structures. Bal et al. [17] also suggested probabilistic distributions for the beam depth, but no information has been provided with regards to the correlation between the depth and length of the
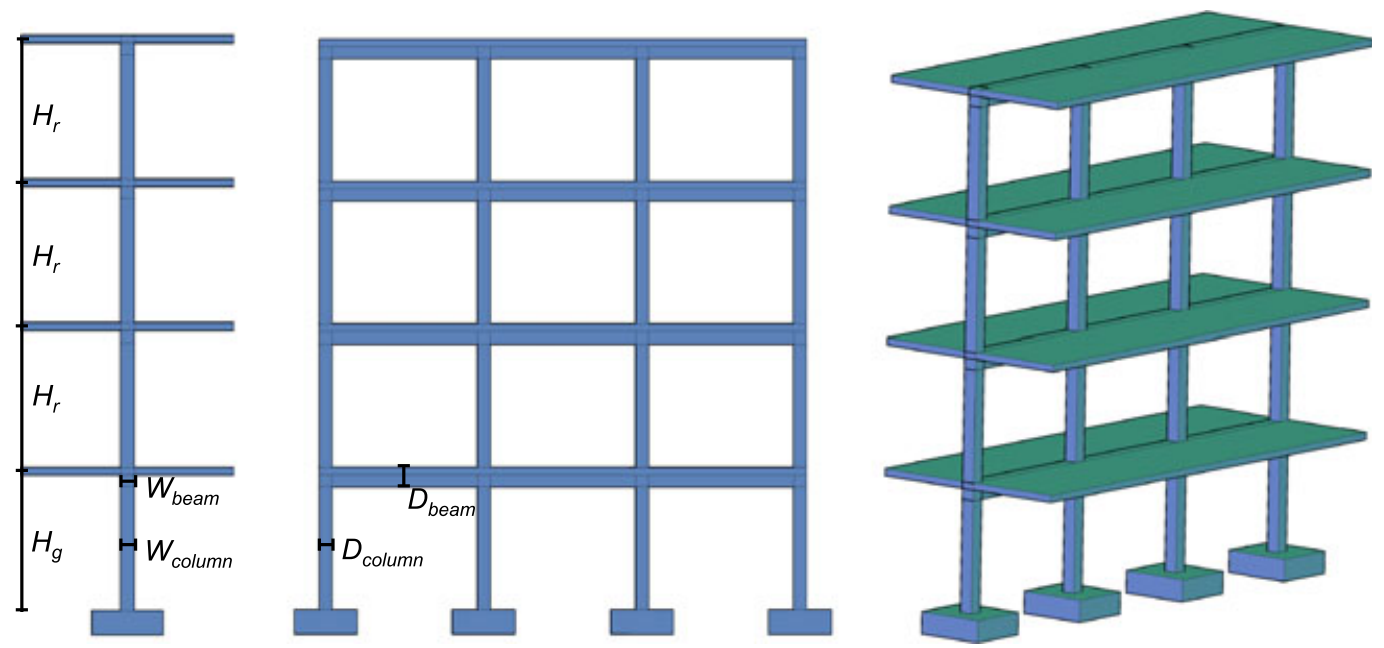

Figure 2. Schematic view of the RC frame model: front (left), side (center), and isometric view (right).

Table I. Probabilistic distributions of the material and geometrical properties.

\begin{tabular}{llccccc}
\hline Parameter & Symbol & Mean & COV & A $^{*}$ & B $^{*}$ & Type of distribution \\
\hline Steel modulus $(\mathrm{GPa})$ & $E_{\mathrm{y}}$ & 210 & $5 \%$ & - & - & Normal \\
Steel yield strength $(\mathrm{MPa})$ & $f_{\mathrm{y}}$ & 371.1 & $24 \%$ & - & - & Normal \\
Concrete strength (MPa) & $f_{\mathrm{c}}$ & 16.7 & $50 \%$ & 2 & 40 & Gamma \\
Regular height $(\mathrm{m})$ & $H_{\mathrm{r}}$ & 2.84 & $8 \%$ & - & - & Lognormal \\
Ground/regular height ratio & $H_{\mathrm{g}} / H_{\mathrm{r}}$ & 1.13 & $14 \%$ & 1 & 1.4 & Exponential \\
Beam length $(\mathrm{m})$ & $L_{\mathrm{beam}}$ & 3.37 & $38 \%$ & - & - & Gamma \\
Column depth $(\mathrm{m})$ & $D_{\text {colum }}$ & 0.49 & $30 \%$ & 0.4 & 1 & Lognormal \\
\hline
\end{tabular}

*A and $\mathrm{B}$ indicate the lower and the upper bounds of the truncated distribution, respectively. 
beams. Thus, independently sampling these two parameters could lead to unrealistic situations (e.g., very long beams with a small depth). A single column depth was sampled for each model.

Once the set of parameters for a given frame was sampled, an automatic process was triggered to calculate beam depth and area of steel of each structural element, for gravity loads only, as was the common practice for many existing buildings (prior to the implementation of the 1998 Turkish seismic design code). The maximum bending moment $\left(M_{\max }\right)$ was computed for each beam on the basis of the appropriate dead and live loads and the following formula was employed for the beam depth calculation:

$$
D_{\text {beam }}=\sqrt{\frac{M_{\text {max }}}{0.15 \times W_{\text {beam }} \times f_{\mathrm{c}}}}
$$

where $W_{\text {beam }}$ stands for the beam width and $f_{\mathrm{c}}$ represents the concrete compressive strength.

The maximum negative and positive bending moment were used to estimate the top and bottom reinforcement steel area $\left(A_{\mathrm{s}}\right)$, respectively, of the beam section by using the following classic formulae:

$$
\begin{gathered}
M_{\text {red }}=\frac{M_{\text {max }}}{W_{\text {beam }} \times D_{\text {beam }}^{2} \times f_{\mathrm{c}}} \\
w=0.973\left(1-\sqrt{1-2.056 \times M_{\text {red }}}\right) \\
A_{\mathrm{s}}=\frac{w \times D_{\text {beam }} \times W_{\text {beam }} \times f_{\mathrm{c}}}{f_{\mathrm{y}}}
\end{gathered}
$$

where $f_{\mathrm{y}}$ represents the steel yield strength. For what concerns the reinforcement steel in the columns, the following formula was used:

$$
A_{\mathrm{s}}=\frac{N-0.85 A_{\mathrm{c}} \times f_{\mathrm{c}}}{f_{\mathrm{y}}}
$$

where $N$ and $A_{\mathrm{c}}$ stand for the axial load and area of concrete in the column section, respectively. A minimum criterion for the area of steel of at least $1 \%$ of the concrete sectional area was established. Once the areas of steel of the beams and columns were computed, a number of reinforcement bars capable of providing the previously estimated amount of steel were attributed to each element, completing the design of the frames.

\subsection{Numerical modelling of the $R C$ frames}

To use the randomly generated RC frames in the various analyses, the developed framework was connected to OpenSees [24], a platform for structural modelling and assessment. Each frame was modelled using a 2D environment, thus considering only 3 degrees of freedom per node (two translational and one rotational) and all the columns and beams were modelled as force-based elements, by using fiber sections to capture the nonlinear behavior of the materials, with a mesh of $5 \times 40$ fibers. The unconfined and confined concrete constitutive relationships were assumed to follow the Kent-Park model modified by Scott et al. [25] with a confinement coefficient equal to 1.15 , whereas the behavior of the steel was represented by the model suggested by Giuffrè and Pinto [26]. The gravity loads were applied in the structure in the form of uniformly distributed loads on the beams, and P-delta effects were considered.

\subsection{Ground motion input}

The selection of the set of accelerograms used for this study was undertaken on the basis of local seismic hazard properties such as range of magnitude and peak ground acceleration, most common 
fault failure mechanism, frequency content, duration, and epicentral distance. This use of suites of accelerograms allows the consideration of the influence of the record-to-record variability of the seismic input on the structural response. Currently there appear to be no formal guidelines for the selection of ground motion records to use in fragility curves generation. Many authors choose to gather sets of natural or synthetic records that are subsequently scaled to cover the range of ground motion levels that might occur in the region of interest $[4,5,27,28]$. However, often the scaling process selected does not introduce changes in other properties of the records such as the frequency content or event duration, which are inherent to the magnitude of the event.

There have been a number of recent advances in the selection of ground motion records to ensure compatibility with the seismic characteristics of the region, while also maintaining the variability [29]. The authors intend to investigate the influence of using such selection methods on the development of vulnerability functions, but for the purposes of the current paper, a decision was taken to employ natural ground motion records because of the wide availability of strong motion databases (e.g. Daphne [30] (Turkey), ESD [31] (Europe), PEER [32] (global), COSMOS [33] (global)) with records that can be applicable to the region from where the characteristics of the RC buildings were compiled. For the selection of the accelerograms, the work of Kalkan et al. [34], in which a probabilistic seismic hazard analysis for the Marmara region was performed, was used to identify the following characteristics of the seismic events:

- Range of magnitude: 6.0 to $7.4 \mathrm{Mw}$;

- Range of distance: 15 to $150 \mathrm{~km}$;

- Rupture mechanism: strike-slip.

A decision was also made not to include records that were at a distance lower than $15 \mathrm{~km}$, with the purpose of avoiding accelerograms with near field effects, where it has been observed that the inelastic spectral displacements can be much larger and with higher variability than the respective elastic response [35]. Another factor that was taken into account was the frequency range featured by each accelerogram. Records that did not cover the full frequency range within this study (i.e., spectral ordinates between 0.05 and $5 \mathrm{~s}$ ) were also excluded. About 100 ground motion records were finally extracted from the ESD [31] and PEER [32] databases. Histograms illustrating the variation of PGA, peak ground velocity (PGV) and Arias Intensity of the selected records are presented in Figure 3.

To understand the variability in the spectral shape and frequency content, the elastic acceleration spectra for 5\% viscous damping were evaluated, as depicted in Figure 4.

\section{PUSHOVER CURVES}

This section presents the derivation of pushover and capacity curves (in terms of spectral acceleration and spectral displacement) for 100 randomly generated frames by using a number of different
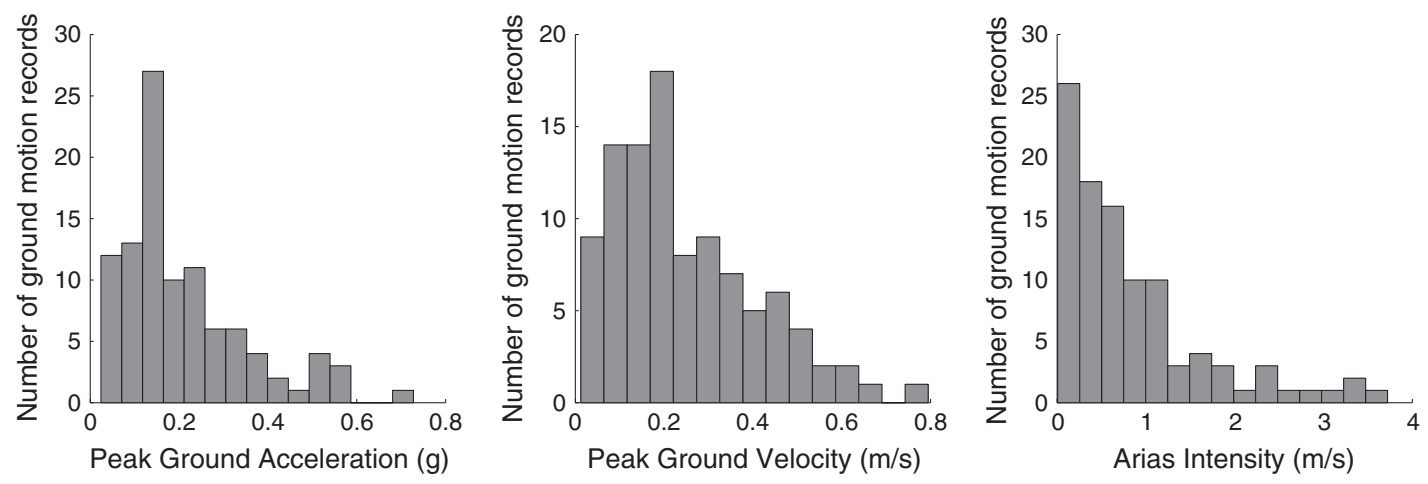

Figure 3. Distribution of the PGA (g), peak ground velocity (PGV) $(\mathrm{m} / \mathrm{s})$, and Arias Intensity $(\mathrm{m} / \mathrm{s})$ for the set of ground motion records. 


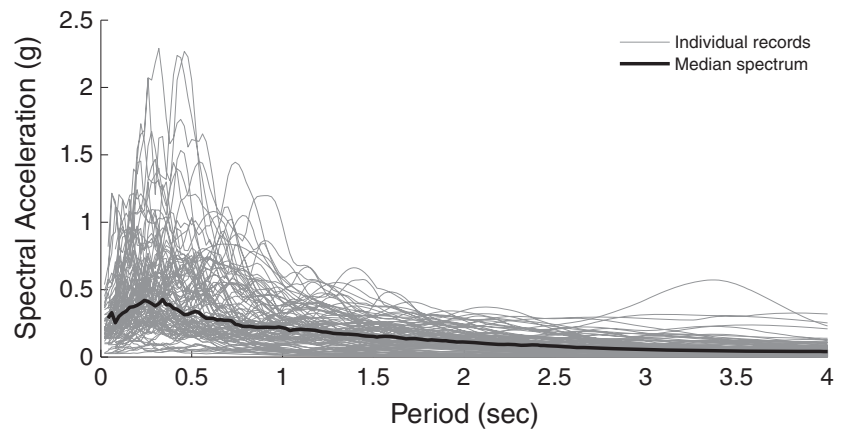

Figure 4. Acceleration spectra $(\mathrm{g})$ versus period of vibration (s) for the set of ground motion records.

methodologies and assumptions. Further discussion of the variability in the capacity curves from the different procedures is presented in Section 6.1.

\subsection{Conventional pushover}

A conventional pushover curve describes the relation between base shear and roof displacement of a MDOF structure when an increasing lateral force is applied. The use of pushover curves in earthquake engineering somewhat originates from the pioneering work or Gulkan and Sozen [36], in which simplified SDOF models were created to represent MDOF structures and used in nonlinear static analysis. This methodology has many advantages and disadvantages that have been the focus of several studies for the past years, in particular that by Krawinkler and Seneviratna [37]. The latter stated that such approach is a valuable tool in vulnerability assessment because of its simplicity, ease of use, and reduced running time, despite its inability to reproduce certain phenomena such as viscous damping, strength deterioration or pinching effect. These authors also highlighted the constant loading pattern as one of the weakest points of this method, as it ignores some deformation modes that are propelled by dynamic response and inelastic response characteristics. This invariant loading pattern usually adopts a uniform, triangular or a first deformation mode shape. In this study, the first two patterns were considered but not the latter, because the regularity of the RC frames led to a first deformation mode approximately of a triangular shape, thus leading to the same structural behavior. Instead, a decision was taken to apply a modal loading pattern with the resulting shape from the contribution of the first three modes of vibration.

The transformation of the pushover curve from the MDOF system to a capacity curve in terms of spectral acceleration $(\mathrm{Sa})$ versus spectral displacement $(\mathrm{Sd})$ for an equivalent SDOF structure can be carried out in various ways, under the condition that the deformed shape of the structure is not significantly altered during the dynamic loading. The roof displacement has been converted to $\mathrm{Sd}$ herein on the basis of the participation factor of the first mode of vibration, whereas the base shear has been reduced to Sa using the same factor and the first modal mass. One hundred capacity curves were derived for the randomly generated RC frames, and the results are presented in Figure 5, along
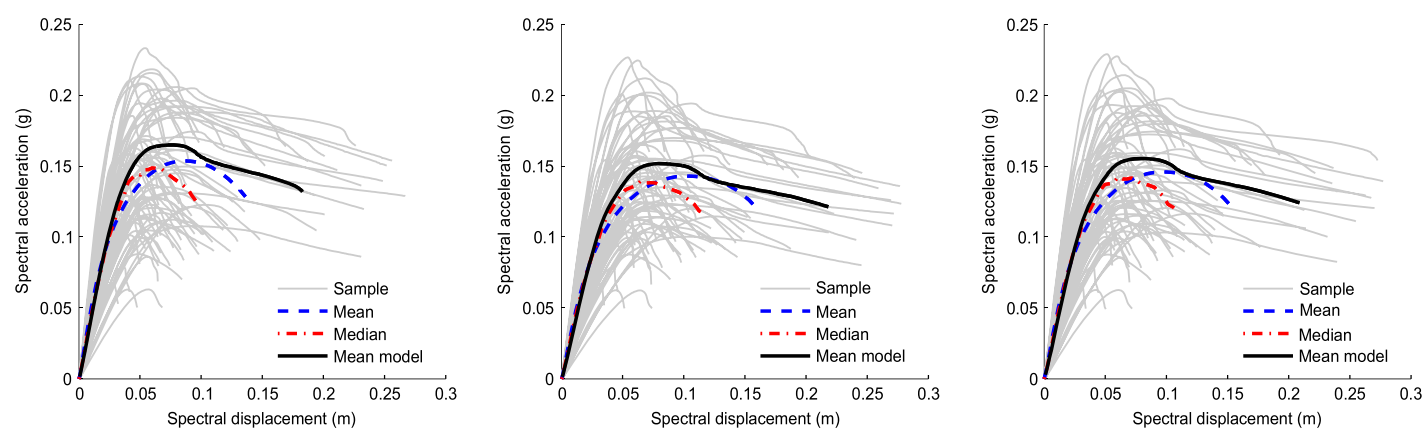

Figure 5. Capacity curves using a uniform (left), triangular (center), and multi-modal (right) loading pattern. 
with the mean and median capacity curves. A single RC frame was also modelled using the mean material and geometric properties (Table I), and the resulting capacity curve is also presented in the same figure.

Regardless of the loading pattern, the results show a very large dispersion in the capacity of the RC frames, strengthening the idea that using a single or few structures to represent a building typology might be insufficient to properly capture their characteristics. The mean $(\mu)$ and associated coefficient of variation $(\mathrm{CoV})$ for each limit state spectral displacements and accelerations in the capacity curves (i.e., the spectral ordinates at which each limit state is reached) considering all of the $\mathrm{RC}$ frames are presented in Table II for the purpose of comparing the different load profiles that have been applied.

\subsection{Adaptive pushover}

As an attempt to overcome some of the previously mentioned shortcomings of conventional pushover, several authors [38-40] have developed adaptive or fully adaptive pushover procedures. These innovative techniques have the advantage of better accounting for stiffness degradation, influence of higher mode effects, and spectral amplifications because of ground motion frequency content. In this method, instead of applying an invariant load vector, the structural properties of the model are evaluated at each step of the analysis, and the loading pattern is updated accordingly. In this way, the variation in the structural stiffness at different deformation levels, and consequently the system degradation and period elongation can be accounted for. The only apparent drawback of this methodology can be the additional computation time required to assess the structural characteristics at every step.

In this study, a displacement-based adaptive pushover (DAP [40]) technique was used, in which an SRSS approach was employed in the modal combination to update the lateral load profile. It was decided that considering other modal combinations techniques such as CQC or ABSolute would not bring any benefit to this study, because the RC frames are highly regular with periods of vibration for each mode that are sufficiently distinct from each other. One hundred capacity curves were derived for the randomly generated RC frames, as well as for the frame model with the mean characteristics. Figure 6 and Table III present these results considering the complete sample of RC frames.

A large scatter in the capacity of the RC frames is still observed but in this case the capacity curve obtained using the model with the mean characteristics is much closer to the mean of the capacity curves. In the work of Akkar et al. [6], JICA [41], and Bogaziçi [42], several capacity curves were derived for common building typologies in Turkey (comparable with the one that is being considered herein), and similar results were obtained in terms of roof displacement and base shear capacity.

\subsection{Convergence in the statistics}

When using a Monte Carlo approach to randomly generate portfolios of buildings, it is important to ensure that convergence in the results is achieved. In the study presented herein, it was necessary to understand how many RC frames would have to be generated, to ensure that additional specimens would not alter the statistics of the sample, within a certain tolerance. The level of variability in the capacity of the randomly generated RC frames is obviously connected to the variability of the material and geometric properties used in the sampling process. Bal et al. [17] estimated that a

Table II. Mean $(\mu)$ and coefficient of variation $(\mathrm{CoV}-\%)$ of the Sd and Sa for each limit state per loading pattern.

\begin{tabular}{|c|c|c|c|c|c|c|c|c|c|c|c|c|}
\hline & \multicolumn{4}{|c|}{ Uniform } & \multicolumn{4}{|c|}{ Triangular } & \multicolumn{4}{|c|}{ Multi-modal } \\
\hline & \multicolumn{2}{|c|}{$\mathrm{Sd}(\mathrm{m})$} & \multicolumn{2}{|c|}{$\mathrm{Sa}(\mathrm{g})$} & \multicolumn{2}{|c|}{$\mathrm{Sd}(\mathrm{m})$} & \multicolumn{2}{|c|}{$\mathrm{Sa}(\mathrm{g})$} & \multicolumn{2}{|c|}{$\mathrm{Sd}(\mathrm{m})$} & \multicolumn{2}{|c|}{$\mathrm{Sa}(\mathrm{g})$} \\
\hline & $\mu$ & $\mathrm{CoV}$ & $\mu$ & $\mathrm{CoV}$ & $\mu$ & $\mathrm{CoV}$ & $\mu$ & $\mathrm{CoV}$ & $\mu$ & $\mathrm{CoV}$ & $\mu$ & $\mathrm{CoV}$ \\
\hline Limit state 1 & 0.030 & 23.3 & 0.119 & 31.9 & 0.035 & 22.5 & 0.112 & 30.0 & 0.033 & 22.4 & 0.114 & 30.3 \\
\hline Limit state 2 & 0.064 & 32.0 & 0.158 & 31.6 & 0.08 & 29.9 & 0.149 & 29.9 & 0.072 & 30.5 & 0.151 & 30.5 \\
\hline Limit state 3 & 0.136 & 63.2 & 0.126 & 32.0 & 0.218 & 61.4 & 0.119 & 30.2 & 0.152 & 62.1 & 0.12 & 30.6 \\
\hline
\end{tabular}




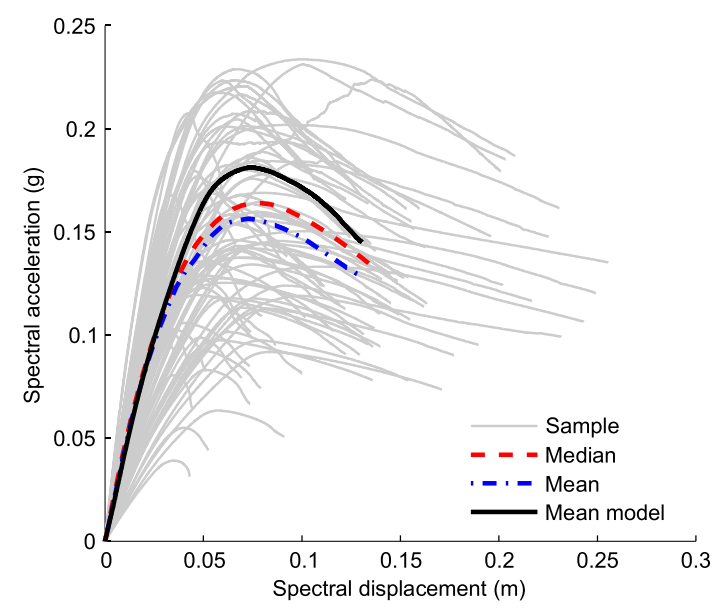

Figure 6. Capacity curves using displacement-based adaptive pushover.

Table III. Mean spectral displacement and acceleration for each limit state.

\begin{tabular}{lcccr}
\hline & \multicolumn{3}{c}{ Adaptive capacity curve } \\
\cline { 2 - 5 } & \multicolumn{2}{c}{ Sd (m) } & \multicolumn{2}{c}{ Sa $(\mathrm{g})$} \\
\cline { 2 - 5 } & $\mu$ & $\mathrm{CoV}$ & $\mu$ & $\mathrm{CoV}$ \\
\hline Limit state 1 & 0.038 & 23.9 & 0.133 & 35.3 \\
Limit state 2 & 0.074 & 30.8 & 0.178 & 35.0 \\
Limit state 3 & 0.131 & 40.9 & 0.142 & 35.4 \\
\hline
\end{tabular}

minimum of 35 buildings would be required in order to have stability in the mean geometric properties. In the present study, 10,000 RC frames were used to estimate the mean capacity curve and because of the very large size of the sample, these statistics were assumed to provide the exact solution. Subsequently, a number of samples with increasing sizes (from 5 to 500) were produced and their mean capacity curves were compared with the results generated using the 10,000 RC frames. This process was repeated several times and, as shown in Figure 7, the variation of the mean error (i.e., the relative difference between the mean curve of each sample and the exact solution) for the uniform-based pushover curves is shown for five repetitions.

As can be seen from Figure 7, every time that a sample of $100 \mathrm{RC}$ frames is reached, no significant changes were observed in the mean results within a 5\% tolerance. The same procedure was also repeated for the other types of pushover curves and an identical number of $\mathrm{RC}$ frames required to achieve convergence was obtained. Thus, throughout this study, a sample of $100 \mathrm{RC}$ frames was always used to test each methodology.

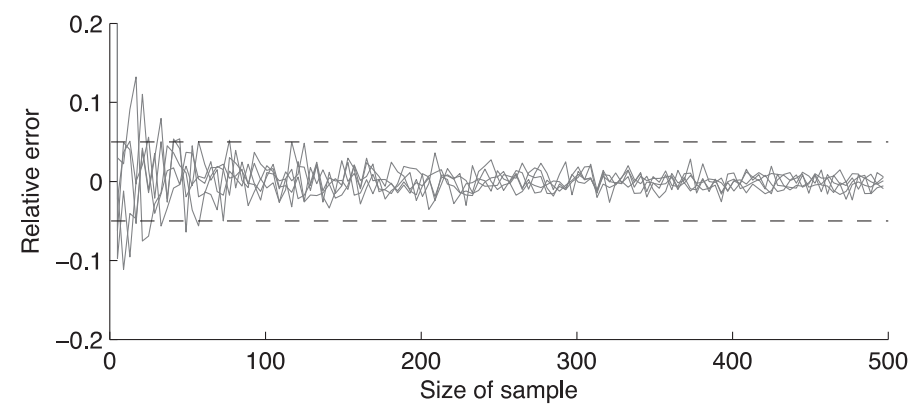

Figure 7. Mean relative error as a function of the size of the sample for five repetitions. 


\section{NONLINEAR STATIC PROCEDURES}

The so-called NSP represent a simplified approach for the assessment of the seismic behavior of structures, included in guidelines such as the ATC-40 [14] and FEMA-440 [15] in the United States or the Eurocode 8 [43] in Europe. In this study, four distinct methodologies were employed: the CSM [14], the coefficient displacement method [15], the N2 method [16], and the adaptive CSM (ACSM) [44], which are further described in the following sections. These methodologies make use of capacity curves in terms of Sa versus Sd (i.e., the capacity of the equivalent SDOF). Each NSP is employed to estimate the target displacement obtained for each ground motion record, and this level of displacement is used to allocate the building in a damage state (according to the limit state criteria define in Section 2). This target displacement can be equated to the maximum roof displacement that would be experienced by the equivalent SDOF structure in a nonlinear dynamic analysis. For each of the 100 randomly generated frames, this displacement is compared with the limit state displacements to identify the damage state of each frame. The distribution of buildings in each global damage state per ground motion record can then be used to derive a fragility function for each limit state by estimating the cumulative percentage of buildings exceeding each limit state and relating this to an intensity measure of the ground motion record. In this study the selected intensity measure type is spectral acceleration (in g) at the yield period of vibration. Because each sampled model as a unique yielding period of vibration, it was decided to use the mean yielding period across all the models. A lognormal distribution is then fit to the data by using least squares regression leading to a logarithmic mean $(\lambda)$ and a logarithmic standard deviation $(\zeta)$ for each fragility function.

Other NSPs such as the modal pushover analysis [45] or the adaptive modal combination procedure [46] have not yet been considered. The main reason for this is that one of the main strengths of such methodologies is the consideration of the influence of higher modes of vibration, which is not relevant in this study, given the high level of regularity and number of stories of the considered building typology.

\subsection{Capacity spectrum method}

The CSM was initially proposed by Freeman et al. [47], and it represents a simplified methodology for many purposes such as the evaluation of a large inventory of buildings, assessment of new or existing structures, or to identify the correlation between damage states and level of ground motion [48]. ATC-40 [14] proposes three different procedures (A, B, and C) for the application of the CSM. However, procedure B adopts some simplifications that might not always be valid and procedure $\mathrm{C}$ has a very strong graphical component, making it difficult to program [49]. Hence, procedure A, which is characterized by its intuitiveness and simplicity, was employed herein. This procedure iteratively compares the capacity and the demands of a structure by using a capacity curve (for the simplified SDOF) and a damped response spectrum, respectively. The ground motion spectrum is computed for a level of equivalent viscous damping that is estimated as a function of the displacement at which the response spectrum crosses the capacity curve to take into account the inelastic behavior of the structure. Iterations are needed until there is a match between the equivalent viscous damping of the structure and the damping applied to the spectrum. The final intersection of these two curves approximates the displacement response of the structure.

The initial proposal of this method was criticized by Fajfar [16], and Chopra and Goel [10] because of its tendency to underestimate the deformation of the structures. Thus, in FEMA-440 [15], some modifications were proposed mainly regarding the calculation of the equivalent viscous damping, which were followed in this study. Another aspect worth further investigating in this method is how well the bilinear curves represent the yielding point for different response spectra, as this value is crucial for the calculation of the equivalent viscous damping.

Applied Technology Council (ATC-40) [15] defines the slope of the first segment of the bilinear curve on the basis of the initial stiffness, which to respect the equal energy dissipated rule (i.e., the area under the capacity curve needs to be equal to the area under the bilinear curve) a yielding point located in the elastic portion of the capacity curve might be obtained. This misrepresentation of the yielding occurs mostly when combining this method with response spectra with low levels of 
ground motion. An alternative for this procedure has been proposed in FEMA-273 [50], in which the slope of the first segment of the bilinear is computed on the basis of the effective stiffness, allowing a more realistic shape of the bilinear curves. This aspect is shown in Figure 8 and Figure 9, where the same capacity curve was used against a weak $\left(\mathrm{PGA}=0.74 \mathrm{~m} / \mathrm{s}^{2}\right)$ and a strong $\left(\mathrm{PGA}=1.42 \mathrm{~m} / \mathrm{s}^{2}\right)$ accelerograms, respectively, for each procedure.

A significant discrepancy is observed in the bilinear curves for the "weaker" response spectrum. In fact, in the case where the ATC-40 guidelines were followed, an equivalent viscous damping equal to 8.94\% was obtained, whereas in the second case where the FEMA-273 was used, a lower equivalent damping of $5.91 \%$ was attained. This poor performance of the ATC-40 procedure for response spectra with low ground motion was also observed in the work of Lin et al. [51]. With regards to the second situation in which a stronger spectrum is employed, both methods seem to provide reasonable results (equivalent damping of $13.21 \%$ and $12.30 \%$ for ATC-40 and FEMA-273, respectively). Despite the fact that FEMA-273 recommendations seem to lead consistently to more reasonable results, it was decided to follow the ATC-40 procedure regarding the bilinearisation to evaluate the practices that currently seem more common in use.

The capacity curves computed for all the RC frames, by using the different pushover methods presented in the previous section, were used with this NSP to derive fragility functions for each limit state, the lognormal parameters of which are presented in Table IV.

\subsection{Displacement coefficient method}

The DCM represents a methodology for the assessment of the seismic response of a building, proposed initially in ATC-40 [14] and further developed in FEMA-440 [15]. This method consists of modifying
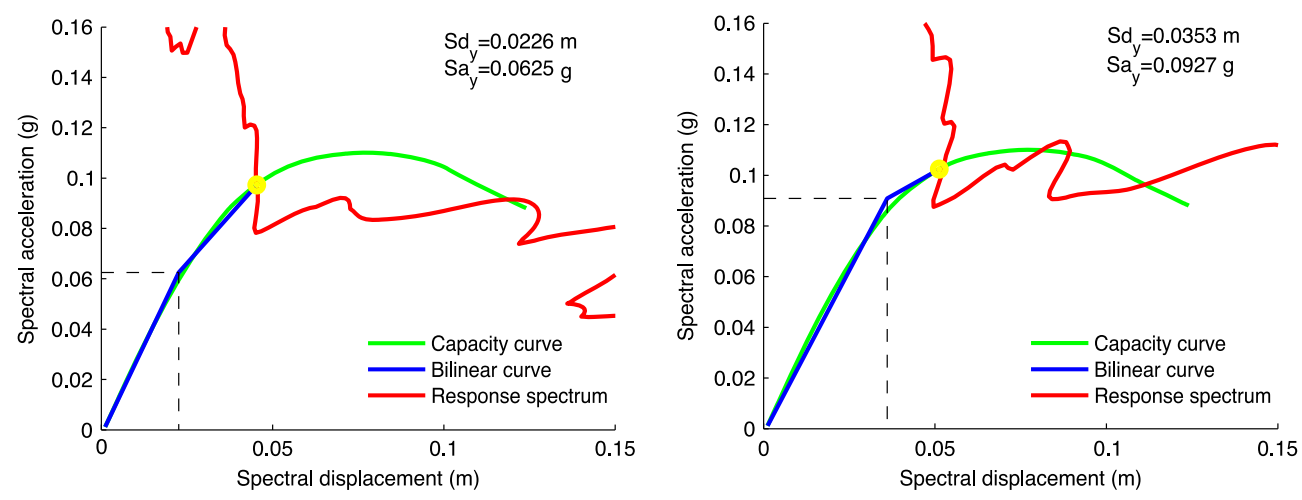

Figure 8. Bilinear curves according to ATC-40 (left) and FEMA-273 (right) for a "weak" response spectrum.
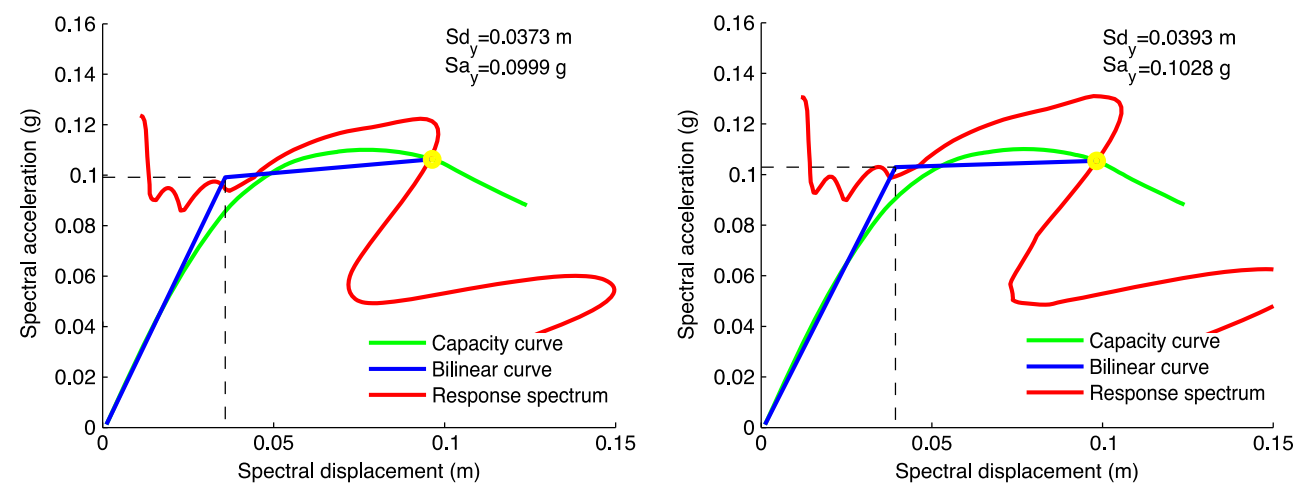

Figure 9. Bilinear curves according to ATC-40 (left) and FEMA-273 (right) for a "strong" response spectrum. 
Table IV. Lognormal parameters of the fragility functions produced using the capacity spectrum method.

\begin{tabular}{|c|c|c|c|c|c|c|c|c|}
\hline & \multicolumn{2}{|c|}{ Uniform } & \multicolumn{2}{|c|}{ Triangular } & \multicolumn{2}{|c|}{ Modal } & \multicolumn{2}{|c|}{ DAP } \\
\hline & $\lambda(\mathrm{g})$ & $\zeta(\mathrm{g})$ & $\lambda(\mathrm{g})$ & $\zeta(\mathrm{g})$ & $\lambda(\mathrm{g})$ & $\zeta(\mathrm{g})$ & $\lambda(\mathrm{g})$ & $\zeta(\mathrm{g})$ \\
\hline Limit state 1 & -2.071 & 0.225 & -2.121 & 0.261 & -2.169 & 0.259 & -2.070 & 0.317 \\
\hline Limit state 2 & -1.439 & 0.323 & -1.364 & 0.254 & -1.438 & 0.285 & -1.327 & 0.291 \\
\hline Limit state 3 & -1.084 & 0.575 & -1.043 & 0.508 & -1.043 & 0.552 & -0.975 & 0.408 \\
\hline
\end{tabular}

DAP, displacement-based adaptive pushover.

the elastic spectral displacement for the effective fundamental period (extracted from the capacity curve), according to four coefficients. These four parameters have the purpose of introducing the effect of the difference in the response of the SDOF and the MDOF systems $\left(C_{0}\right)$, the variation between elastic and inelastic response $\left(C_{1}\right)$, possible degradation of stiffness and energy dissipation $\left(C_{2}\right)$, and the influence of P-delta effects $\left(C_{3}\right)$. The resulting maximum displacement can be determined through the following formula:

$$
\delta_{t}=C_{0} C_{1} C_{2} C_{3} S a \frac{T_{\mathrm{e}}^{2}}{4 \pi^{2}}
$$

where $S a$ stands for the spectral acceleration response for the elastic period $\left(T_{\mathrm{e}}\right)$. These coefficients are tabled in FEMA-440 and have been derived based on statistics from dynamic analysis of SDOF models with various characteristics. It can be applied to new or existing buildings, that are regular and do not have adverse torsional or multimode effects.

The capacity curves computed for all the RC frames, by using the different pushover methods presented in the previous section, were used with this NSP to derive fragility functions for each limit state, the lognormal parameters of which are presented in Table V.

\subsection{N2 method}

Fajfar [16] firstly proposed this simplified nonlinear procedure for the estimation of the seismic response of structures. It is somehow similar to the CSM as it also uses capacity curves and response spectra, but it differs in the fact that it uses inelastic spectra rather than elastic overdamped spectra for an equivalent viscous damping and period. Moreover, it also has the distinct aspect of assuming an elasto-perfectly plastic force-displacement relationship in the construction of the bilinear curve.

To estimate the target displacement within this methodology, it is necessary to assess whether the SDOF structure is in the short-period or medium/long-period ranges. If the structure is in the latter category, it is assumed that the target displacement is equal to the elastic spectral displacement for the fundamental period of the idealized SDOF. If on the other hand it is located in the short-period range, a procedure is carried out to check if the capacity of the SDOF at the yielding point (taken from the bilinear curve) is lower than the spectral acceleration response for the same period. If this is verified, then the structure is assumed to have an elastic response and once again, the target displacement will be equal to the elastic spectral displacement for the fundamental period. In case

Table V. Lognormal parameters of the fragility functions produced using the displacement-based adaptive pushover.

\begin{tabular}{|c|c|c|c|c|c|c|c|c|}
\hline & \multicolumn{2}{|c|}{ Uniform } & \multicolumn{2}{|c|}{ Triangular } & \multicolumn{2}{|c|}{ Modal } & \multicolumn{2}{|c|}{ DAP } \\
\hline & $\lambda(\mathrm{g})$ & $\zeta(\mathrm{g})$ & $\lambda(\mathrm{g})$ & $\zeta(\mathrm{g})$ & $\lambda(\mathrm{g})$ & $\zeta(\mathrm{g})$ & $\lambda(\mathrm{g})$ & $\zeta(\mathrm{g})$ \\
\hline Limit state 1 & -2.133 & 0.269 & -2.055 & 0.194 & -2.126 & 0.296 & -2.080 & 0.292 \\
\hline Limit state 2 & -1.424 & 0.376 & -1.384 & 0.383 & -1.394 & 0.376 & -1.471 & 0.362 \\
\hline Limit state 3 & -0.932 & 0.607 & -0.856 & 0.673 & -0.882 & 0.660 & -0.823 & 0.526 \\
\hline
\end{tabular}


the capacity is higher than the response for the yielding point, the structure is assumed to have an inelastic response and the following formula is employed to determine the target displacement:

$$
\delta_{t}=\frac{S d\left(T_{\mathrm{el}}\right)}{q_{\mathrm{u}}}\left(1+\left(q_{\mathrm{u}}-1\right) \frac{T_{\mathrm{c}}}{T_{\mathrm{el}}}\right) \geqslant S d\left(T_{\mathrm{el}}\right)
$$

where $\operatorname{Sd}\left(T_{\mathrm{el}}\right)$ stands for the spectral displacement for the fundamental period of the idealized SDOF $\left(T_{\mathrm{el}}\right), T_{\mathrm{C}}$ stands for the corner period and $q_{\mathrm{u}}$ represents the ratio between the spectral acceleration for $T_{\mathrm{el}}$ and the acceleration at the yielding point. Considering the capacity curves computed for all the $\mathrm{RC}$ frames for the different pushover methods presented in the previous section, this NSP was used to derive fragility functions for each limit state, the lognormal parameters of which are presented in Table VI.

\subsection{Adaptive capacity spectrum method}

This NSP proposed by Casarotti and Pinho [44] allows the estimation of the seismic response of structures by using a fully adaptive perspective. Pushover curves are generated following a displacement-based adaptive procedure (as described in Section 3.2), but instead of using any elastic or inelastic mode of vibration to convert the MDOF pushover curve to the equivalent SDOF system, the deformed shape at every step is used, leading to a more realistic equivalent capacity curve. Then, an iterative process identical to that described for the CSM has been employed to estimate the target displacement. This method also uses equivalent viscous damping to take into account the nonlinear behavior of the structure; however, unlike CSM, no specific damping model has been suggested. From the many existing damping models, it was decided to apply the one by Priestley et al. [52], as it seemed to provide more accurate results in a parametric study carried out by Casarotti et al. [12]. The lognormal parameters of the fragility functions computed combining this method with the previously presented capacity curves for the adaptive pushover method are presented in Table VII. In Figure 10, the scatter used to derive each fragility function is displayed along with the associated curve. Each point represents the cumulative percentage of buildings in a given damage state for a certain ground motion record. For example, a given record $\left(S a_{\mathrm{el}}=0.14 \mathrm{~g}\right)$ led to $88 \%$ of the frames that exceeded the first limit state, $30 \%$ that exceeded the second limit state, and $4 \%$ that collapsed (exceeded limit state 3 ).

Table VI. Lognormal parameters of the fragility curves produced using the N2 method.

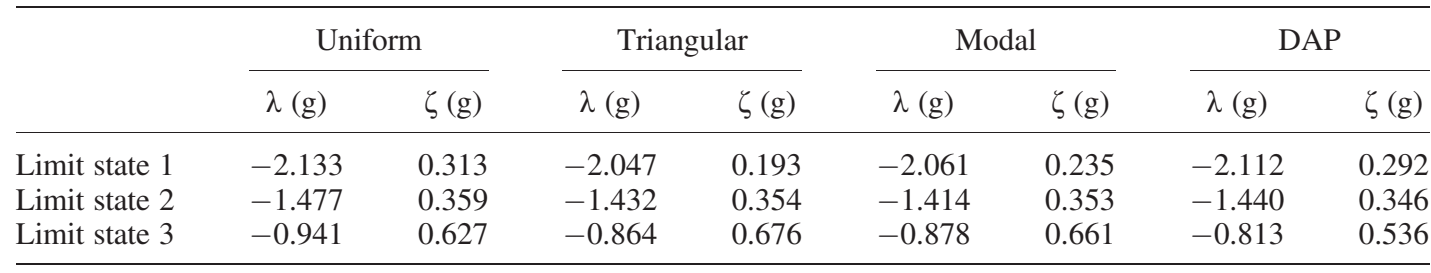

DAP, displacement-based adaptive pushover.

Table VII. Lognormal parameters of the fragility functions by using adaptive capacity spectrum method.

\begin{tabular}{lcr}
\hline & $\lambda(\mathrm{g})$ & $\zeta(\mathrm{g})$ \\
\hline Limit state 1 & -2.065 & 0.289 \\
Limit state 2 & -1.419 & 0.422 \\
Limit state 3 & -0.882 & 0.566 \\
\hline
\end{tabular}




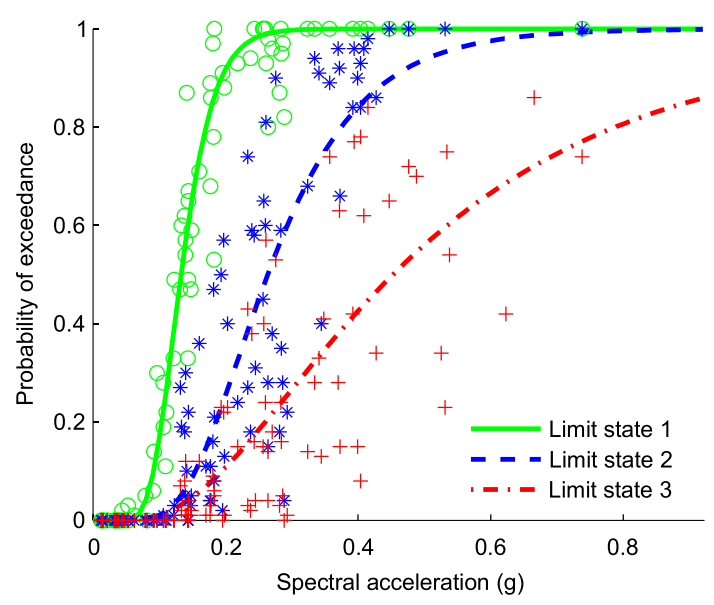

Figure 10. Fragility functions by using adaptive capacity spectrum method.

\section{NONLINEAR DYNAMIC ANALYSIS}

Nonlinear dynamic analysis, when adequately used, tends to be considered as the most accurate and reliable methodology to estimate the seismic response of structures. The requirements around this approach in comparison with the previously presented NSPs are considerably more demanding, mainly on the level of detail of the model, the necessity to represent the masses in the structure, the need to model the equivalent viscous damping, the definition of time integration algorithms, and the treatment of the ground motion input. This higher level of complexity comes also with a significant increase in the computation time, and frequent difficulties with convergence in the analyses.

In this study, nonlinear time history analyses were performed for the 100 randomly generated frames by using the set of ground motion records presented in Section 2.3. As mentioned previously, the maximum roof displacement for each record was compared with the limit state displacements to identify the damage state of the structure. To substantially reduce the computation time of each analysis, these accelerograms were filtered and trimmed on the basis of the 5\% maximum PGA threshold, as discussed by Bommer and Pereira [53]. The resulting fragility functions are presented in Figure 11, and their lognormal parameters are given in Table VIII.

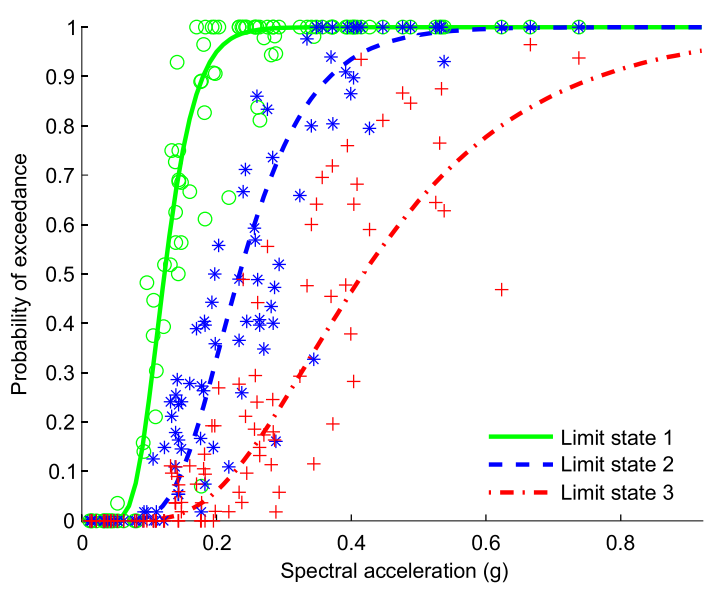

Figure 11. Fragility functions by using dynamic analysis. 
Table VIII. Lognormal parameters of the fragility functions by using nonlinear dynamic analysis.

\begin{tabular}{lcr}
\hline & $\lambda(\mathrm{g})$ & $\zeta(\mathrm{g})$ \\
\hline Limit state 1 & -2.098 & 0.298 \\
Limit state 2 & -1.452 & 0.354 \\
Limit state 3 & -0.833 & 0.504 \\
\hline
\end{tabular}

\section{DISCUSSION OF RESULTS}

\subsection{Variability in the capacity curves}

With regard to the variation of the capacity curves based on their method of calculation, an underestimation of the capacity in most of the randomly generated RC frames was consistently observed when employing conventional pushover procedures in comparison with the adaptive pushover technique. This behavior is probably because in the former approach, the structures may be forced to deform in an "unnatural" manner. It was also noticed that the capacity curve generated using the RC frame following the mean geometric and material properties was significantly different from the mean of the capacity curves from the randomly generated frames. In fact, this capacity curve presented a considerably higher displacement capacity (54\%), which suggests that if such output would be used in seismic risk assessment, the losses could be underestimated. This observation is conditional on the probabilistic distribution of the geometric and material properties proposed by Bal et al. [17] and therefore, it should not be generalized to other building typologies.

Regarding the differences due to the application of the different loading patterns, it was observed that a uniform load led to higher values of base shear capacity (18\%), whilst greater displacement capacity was attained when employing a triangular load (12\%). Such results are in agreement with other studies [13, 54]. Applying a loading pattern based on the contribution of the first three modes of vibration generated intermediate results, as expected. With regard to the variations between conventional and adaptive techniques, it is possible to conclude that the latter approach led to slightly superior base shear capacity (12\%) and significantly higher roof displacements (33\%). These differences in the statistics will naturally have a direct impact on the associated fragility functions, as explained in the following section. In Figure 12, the mean and median capacity curves are presented, as well as the capacity curve generated using the mean characteristics of the RC frames.

\subsection{Variability in the fragility functions}

To investigate the impact of the various pushover methods and NSPs on the fragility, all of the computed functions were plotted together, as illustrated in Figure 13. For the sake of clarity, these curves were separated according to the limit states.

The evaluation of the curves between different limit states shows higher variations for the third limit state, and a lower sensitivity regarding the chosen methodology for the first limit state. This aspect is
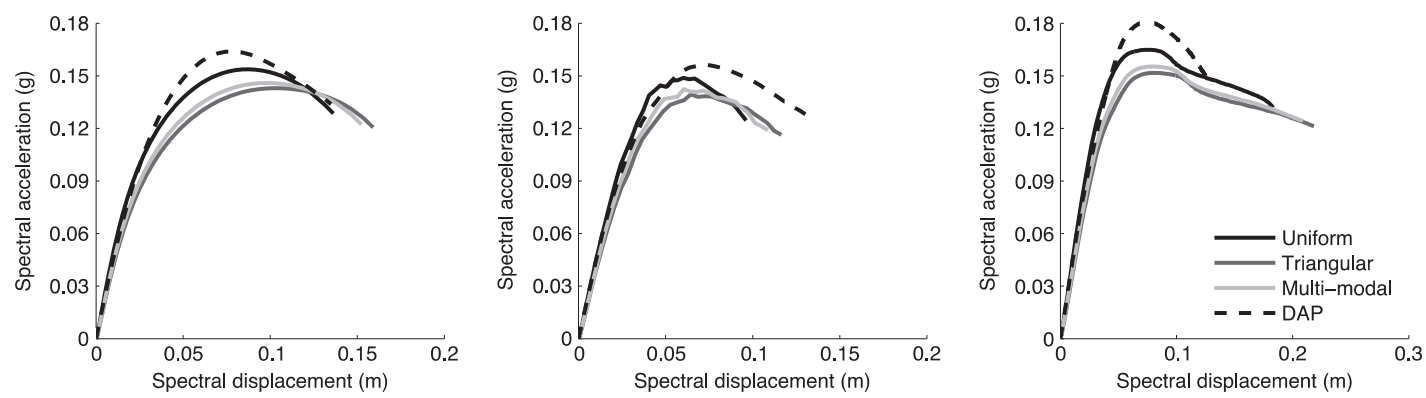

Figure 12. Mean (left) and median (center) capacity curves and capacity curves generated using the mean characteristics of the RC frames (right). 

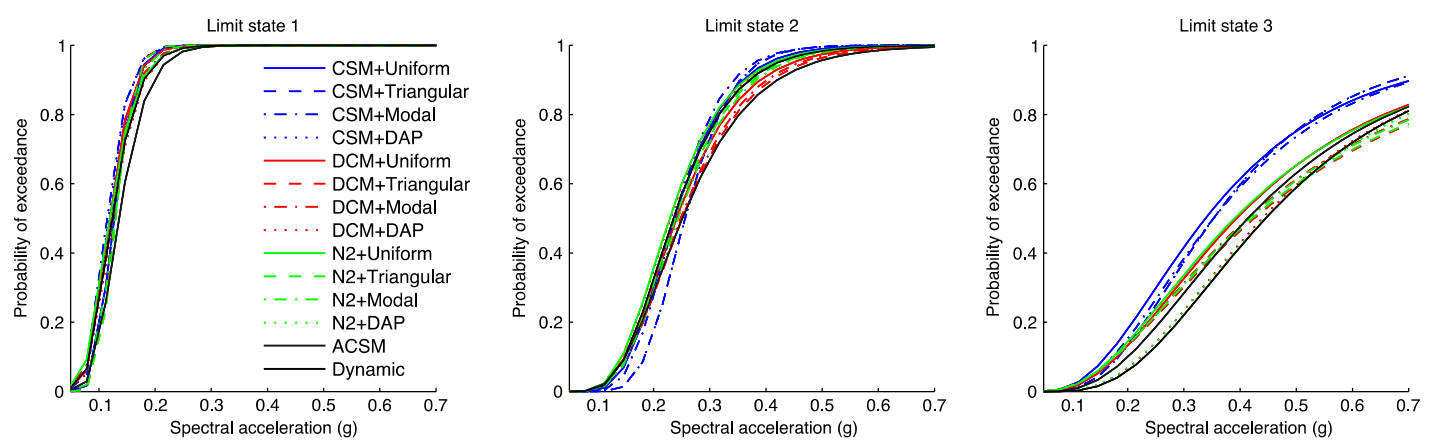

Figure 13. Fragility curves for the first (left), second (center) and third (right) limit states according to the different methodologies.

probably because for low levels of ground motion (when only limit state 1 is reached), the response of the RC frames is mainly elastic. Therefore, each methodology provides similar results. For stronger levels of ground motion, damage begins to occur (reaching limit state 2 and 3) and the RC frames starts to deform nonlinearly. The manner in which each combination of methodology estimates the nonlinear response is different and consequently so will be the associated results.

Regarding the differences in the fragility curves between the various combinations of methodologies, it is fair to state that the CSM systematically overestimated the collapse (limit state 3) fragility, whereas the DCM + DAP and N2 + DAP provided results identical to those obtained using the nonlinear dynamic analysis.

A systematically lower probability of exceedance for limit state 3 has been observed when employing the nonlinear dynamic approach. For higher ground motion values, the target displacement estimated using the NSPs are frequently higher than those obtained from the nonlinear dynamic analysis. Such behavior has also been observed in the work of Pinho et al. [55] and Bhatt and Bento [56], where various NSPs were analyzed for a set of structures by using increasing levels of ground motion intensity. Higher displacement demands lead to a higher number of frames being assigned to collapse when using the NSPs, leading to a higher probability of exceeding limit state 3 .

\subsection{Variability in the vulnerability functions}

Each set of fragility functions was transformed into a vulnerability function (i.e., a probabilistic distribution of loss ratio given an intensity measure level). To do so, for a set of intensity measure levels, each fragility model was used to compute the percentage of buildings in each damage state and these results were multiplied by the associated damage ratios, according to a consequence model. These consequence models establish the relation between physical damage and the ratio between cost of repair and cost of replacement (herein called damage ratio), and can differ significantly based on the region, building typology, and definition of damage states (e.g., Greece [57]; Italy [58]; Turkey [17]; California (HAZUS) [59]). The consequence model will naturally have a direct impact on the shape of the vulnerability function, as it defines the contribution of each damage state to the resulting loss ratio per intensity measure level. In Figure 14, the consequence models employed in this study are represented.

The resulting vulnerability functions from the combination of the different pushover techniques with the various NSPs are presented in Figure 15 (with the HAZUS consequence model) and in Figure 16 (with the Turkish [17] consequence model). The vulnerability curve resulting from the nonlinear dynamic analysis has also been included for comparison purposes. For the sake of clarity, the vulnerability functions have been organized according to the nonlinear static procedure.

Through the observation of the results, it is fair to state that despite the differences in the applied analysis, no major discrepancies were obtained in the vulnerability functions across the pushover methods within each NSP. For what concerns the influence of the consequence model, a higher discrepancy was observed between the vulnerability functions by using the HAZUS model [59]. This aspect is connected to the differences in the limit state curves and the weight of each damage 


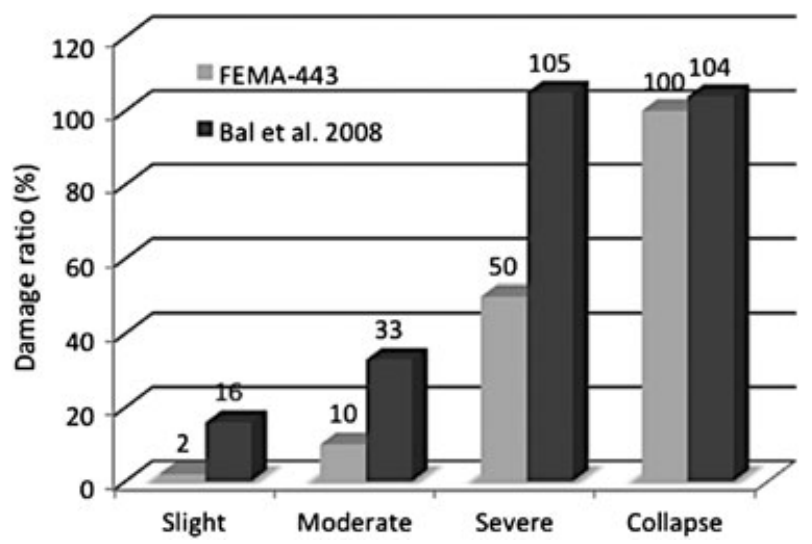

Figure 14. Consequence model for buildings in California (HAZUS) [57] and Turkey [17].
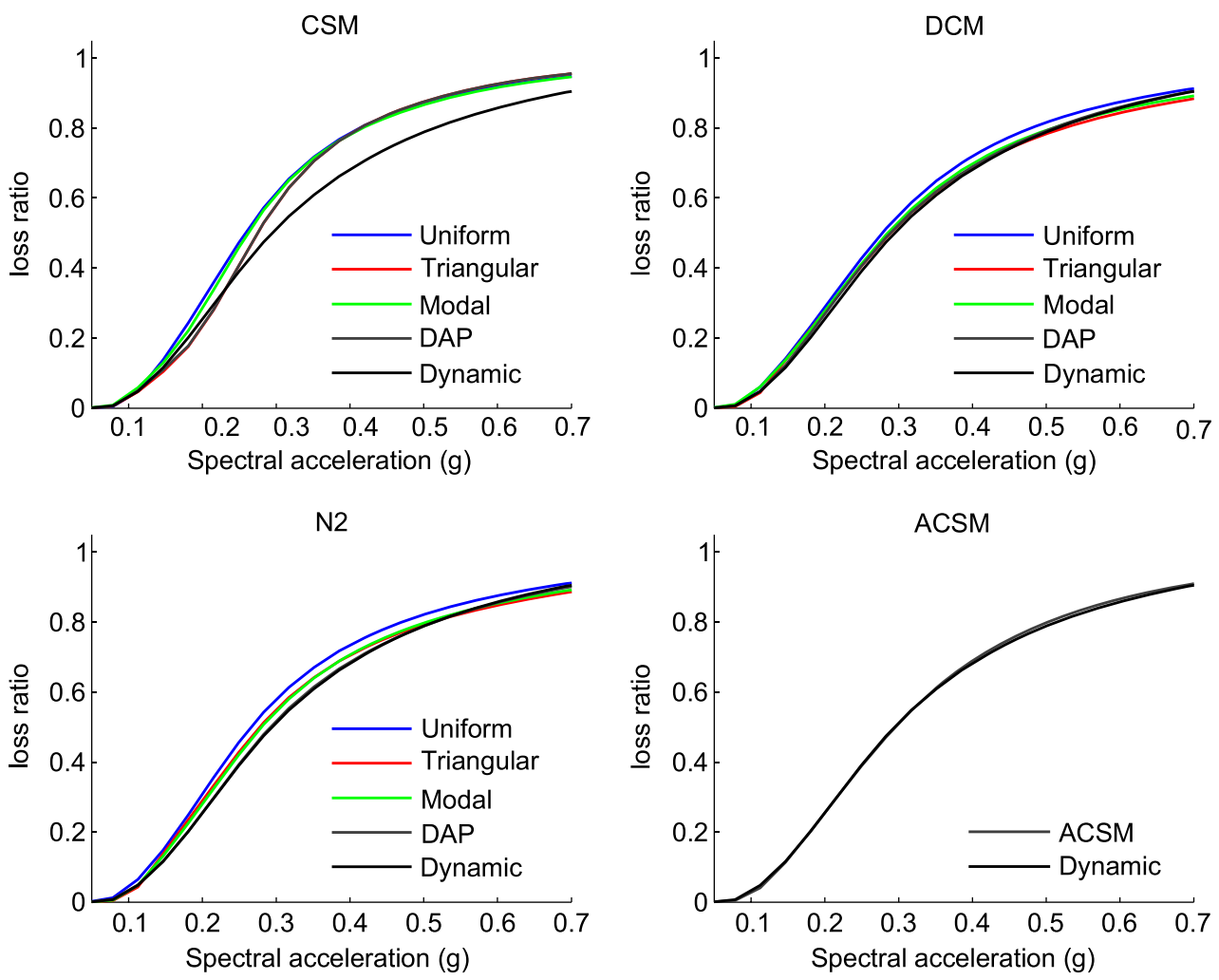

Figure 15. Vulnerability functions per Nonlinear Static Procedure (NSP) using the HAZUS [59] consequence model. CSM, capacity spectrum method; DCM, displacement coefficient method; ACSM, adaptive capacity spectrum method.

state in the resulting loss ratio. In general, the fragility curves for the first two limit states are very similar regardless of the methodology employed to produce them, but for the last limit, state the differences are more pronounced (as shown previously in Figure 13). Hence, a consequence model such as the Turkish [17] one that attributes high damage ratios not just for the last damage state (collapse) but also for the second (moderate) and third (severe), will produce vulnerability functions whose loss ratios is not just influenced by the last damage state. On the other hand, the HAZUS consequence model has a distribution of damage ratios that defines the last damage state (which varies more significantly amongst the different methodologies), as the one that influences the most the resulting loss ratio, leading to higher variations in the vulnerability functions. To yield 

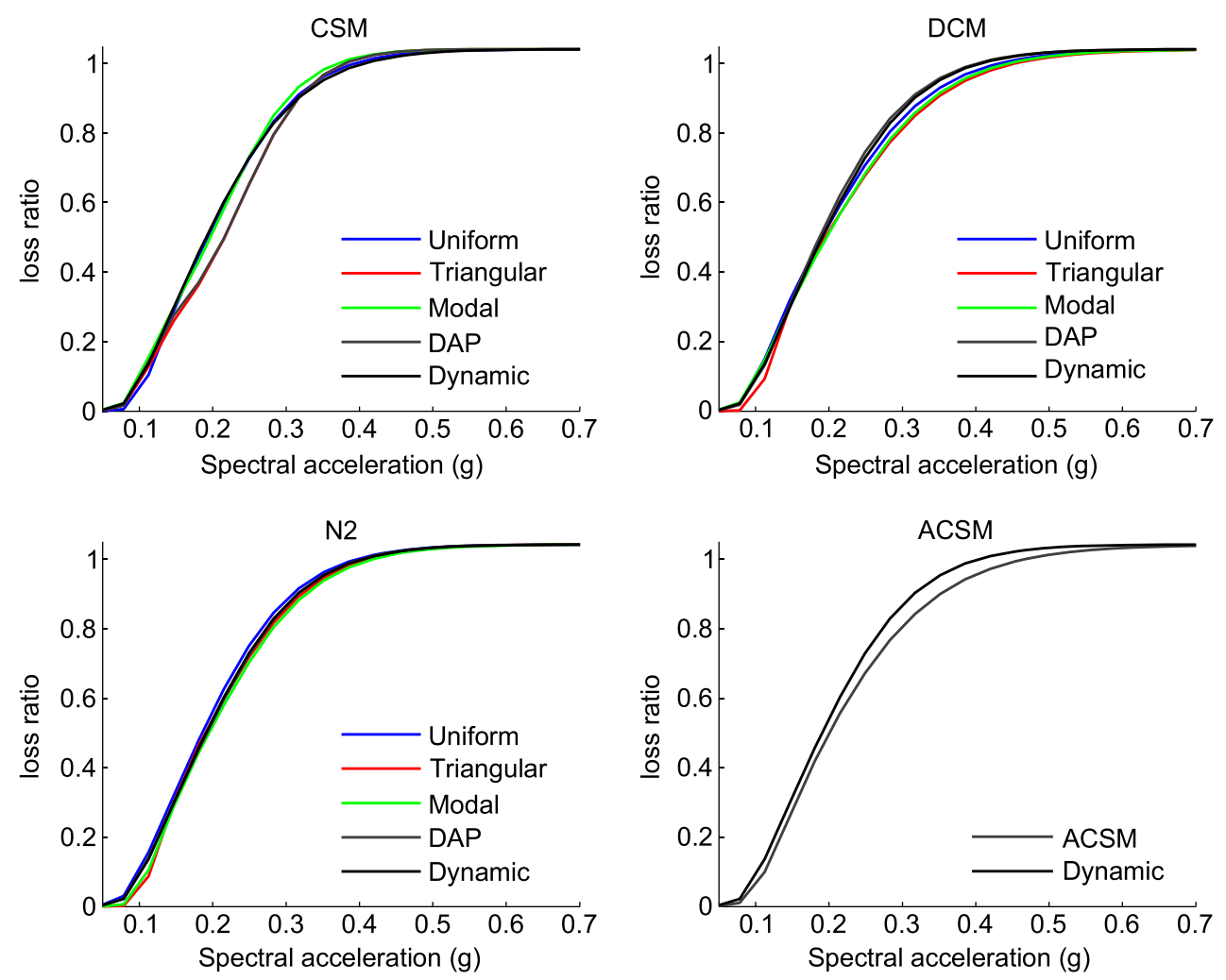

Figure 16. Vulnerability functions by using the Turkish [17] consequence model. CSM, capacity spectrum method; DCM, displacement coefficient method; ACSM, adaptive capacity spectrum method.

conclusions regarding the differences obtained when using different NSPs, the mean vulnerability function for each NSP was derived, as presented in Figure 17.

The functions for which the CSM was employed presented consistently higher loss ratios, whereas those using the N2 and DCM were very similar and presented slightly lower loss ratios with respect to the dynamic analyses. Considering all of the results, the vulnerability function with the lowest loss ratios is obtained when employing the Adaptive CSM, whereas the highest loss ratios are produced when using the CSM combined with uniform-based pushover curves. In fact, a mean and maximum average difference amongst vulnerability functions of $12 \%$ and $18 \%$, respectively, are observed. This underestimation in the capacity of the structures when employing the CSM was also verified in
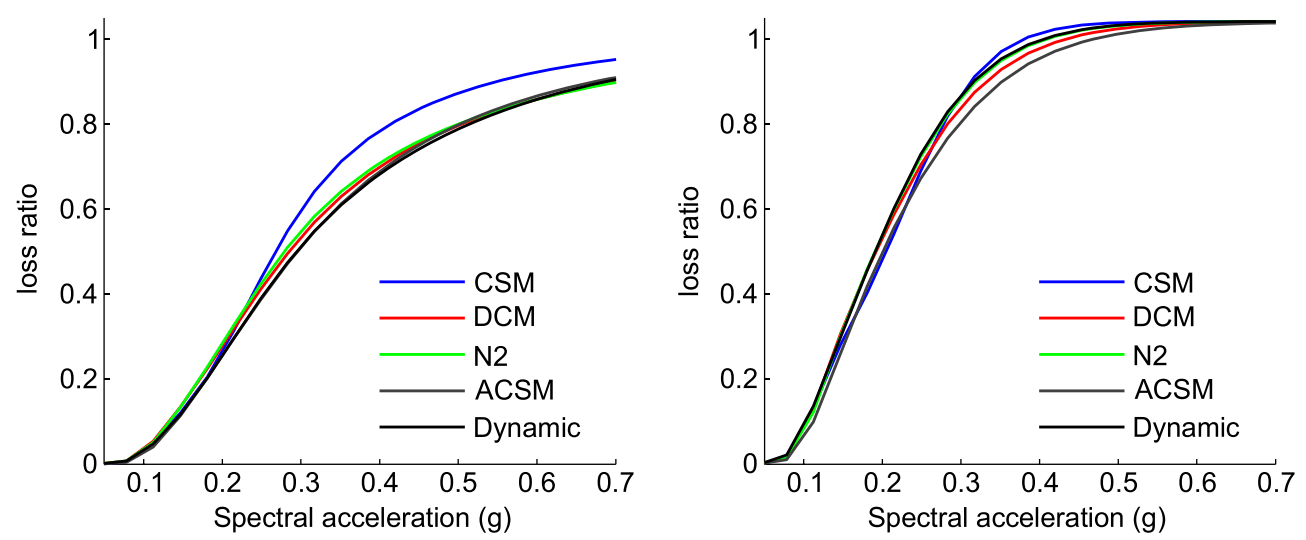

Figure 17. Mean vulnerability function for each NSP according to the HAZUS [59] (left) and Turkish [17] (right) consequence models. CSM, capacity spectrum method; DCM, displacement coefficient method; ACSM, adaptive capacity spectrum method; N2, N2 method. 
an experimental exercise performed by Lin et al. [51], in which the estimated seismic response was $20 \%$ lower than experimental observations. With regards to the differences between the results obtained using the aforementioned combinations and those attained with the nonlinear dynamic analysis, it was observed that the N2 method associated with the adaptive capacity curves led to almost identical results.

\subsection{Variability in seismic risk assessment}

As previously presented, different methodologies to analyze the nonlinear response of structures lead to slightly different vulnerability functions. The influence of these discrepancies in seismic risk assessment was also evaluated within this study. A decision was taken to not just consider only one or a few scenarios (single seismic events), but rather to carry out a probabilistic seismic risk assessment, in which all the possible ruptures for the region of interest are covered; relying only in a set of scenarios could easily lead to ambiguous conclusions, as depending on the magnitude of the events, only certain portions of the vulnerability functions would have been used in the calculations.

The reinforced concrete building portfolio of the metropolitan area of Istanbul was used for the seismic risk assessment. The exposure model is a combination of data from aerial photos taken in 1995 and 1998, and census data from 2000 conducted by the Turkish State Statistics Institute [60], and it follows a $0.005 \times 0.005$ decimal degrees grid. Each grid cell contains the economic value of a set of building typologies, and for this study only the mid-rise RC buildings built before the implementation of the 1998 Turkish design code were considered, as they represent the building class considered herein. With regards to the hazard model, the work of Demircioglu et al. [61] was used, in which a distribution of area and fault sources were compiled for the whole Turkish territory. The combination of a spatially distributed exposure model with a comprehensive seismic hazard model allowed the consideration of a large spectrum of ground motions and, consequently, a full coverage of the vulnerability functions. Figure 18 presents the spatial distribution of building economic value and the ground motion distribution for a hazard map with a $10 \%$ probability of exceedance in 50 years in the Marmara Region.

The exposure model, seismic hazard model and the set of vulnerability functions (generated using the Turkish consequence model) were introduced in the open source software OpenQuake [62], and total loss exceedance curves (representing the aggregate losses of the whole building portfolio) were computed by using each vulnerability function. Then, by using these curves, the average annual loss and the losses for probabilities of exceedance of $1 \%$ and $10 \%$ in 50 years were extracted. The results using the vulnerability function derived through nonlinear dynamic analysis were used as the baseline solution to compute the relative variation of each methodology, as presented in Figure 19.
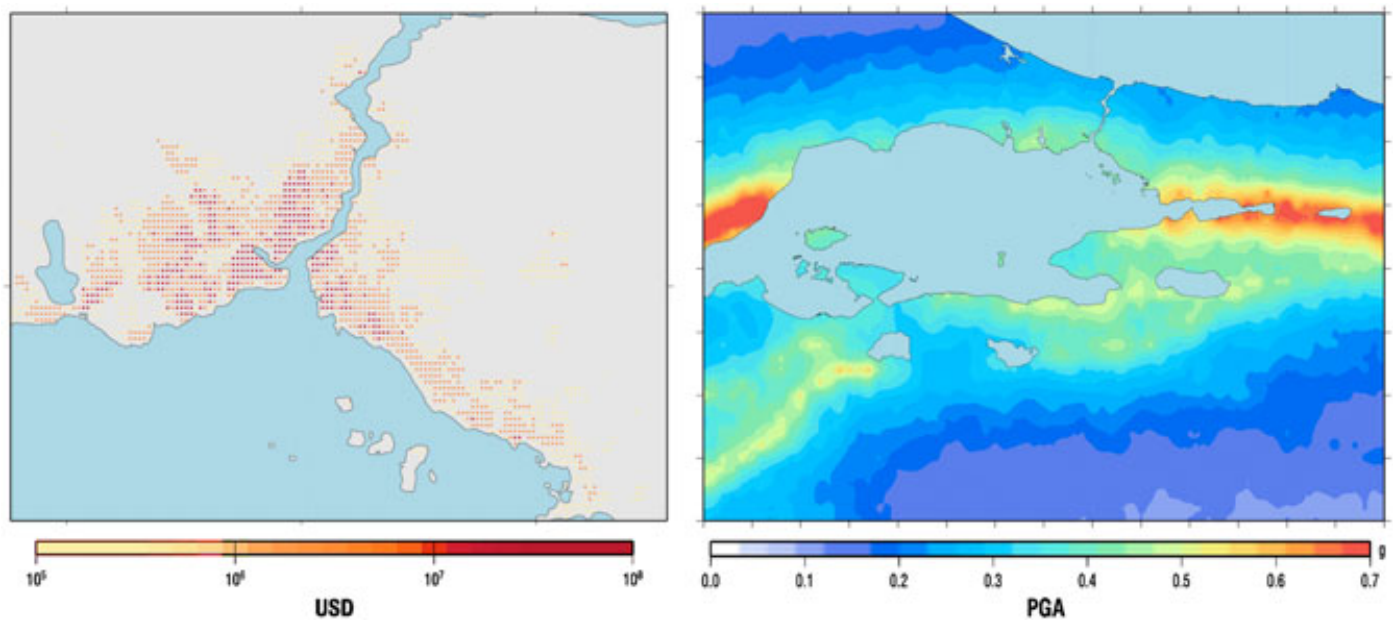

Figure 18. Exposure model for mid-rise RC pre-code buildings in the metropolitan area of Istanbul (left) and hazard map for $10 \%$ probability of exceedance in 50 years (right) for the Marmara region. 

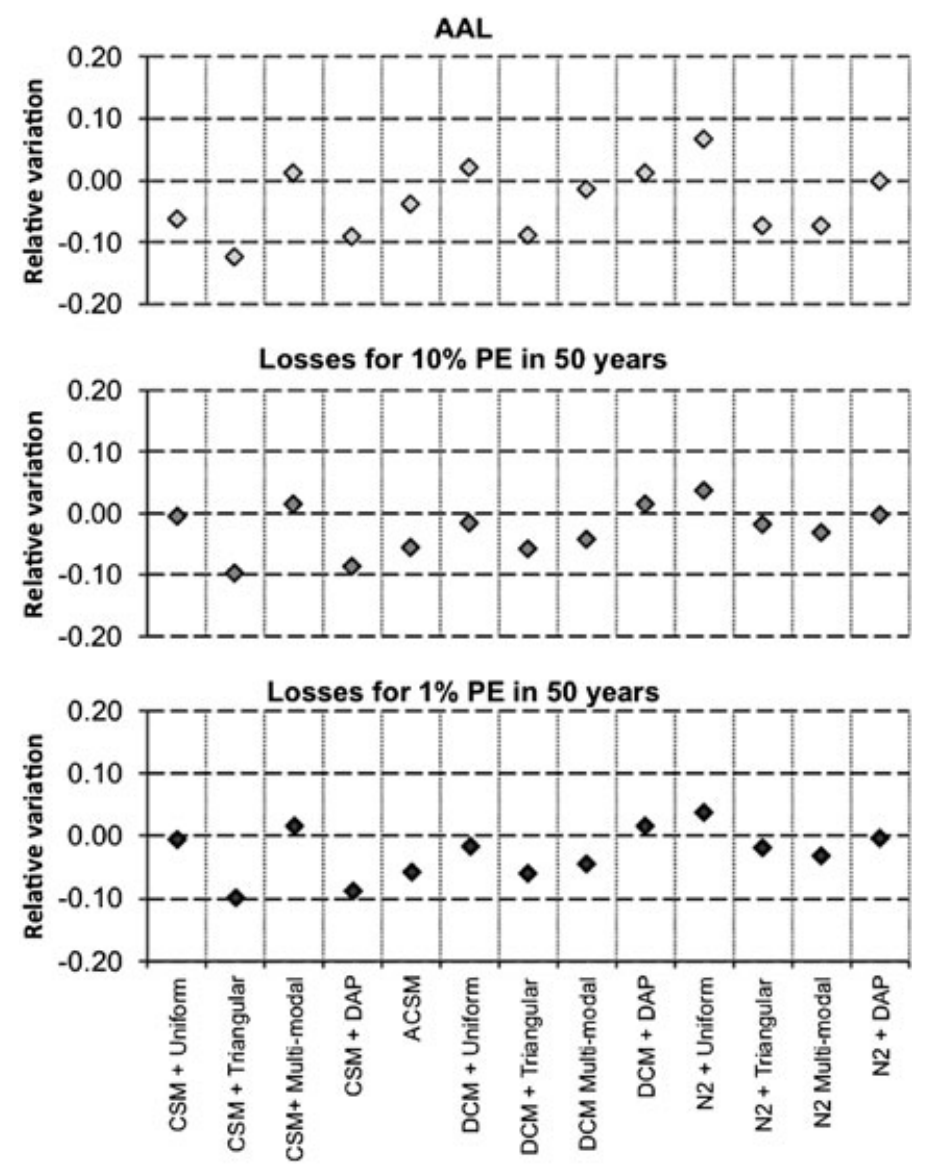

Figure 19. Relative variation in the average annual loss (AAL) (top), level of losses for frequent events (center) and level of losses for rare events (bottom).

The comparison of the seismic risk results revealed slight differences among the different vulnerability methodologies. With regard to the differences between the nonlinear static procedures, a lower variation was observed when employing the N2 method, closely followed by the DCM. Furthermore, within these two procedures, an improvement in the results was found when adaptivebased pushover (DAP) curves were utilized. The ACSM also revealed satisfactory results, with an average variation of $4 \%$.

Regarding the differences between the three seismic risk parameters, the results for the average annual losses showed a slightly higher sensitivity for some of the methods. This risk parameter is highly influenced by the losses because of frequent events, which generally have lower levels of ground motion. Therefore, in the methods that led to vulnerability functions with significantly different loss ratio values in the low spectral acceleration region than those derived using dynamic analysis, a higher relative variation was obtained.

\subsection{Computational performance}

To yield conclusions regarding the balance between reliability and computational efficiency, the required time to complete each vulnerability methodology was registered (from the generation of the one hundred random RC frames until the estimation of the vulnerability functions). The performance provided by each methodology has been normalized with regard to the most computationally efficient one, as presented in Figure 20.

In general, the DCM and N2 represent the most efficient methodologies, falling in the same performance category regardless of the type of pushover curve. The methodologies that rely on the capacity spectrum approach to estimate the seismic response (CSM and ACSM) are more time 


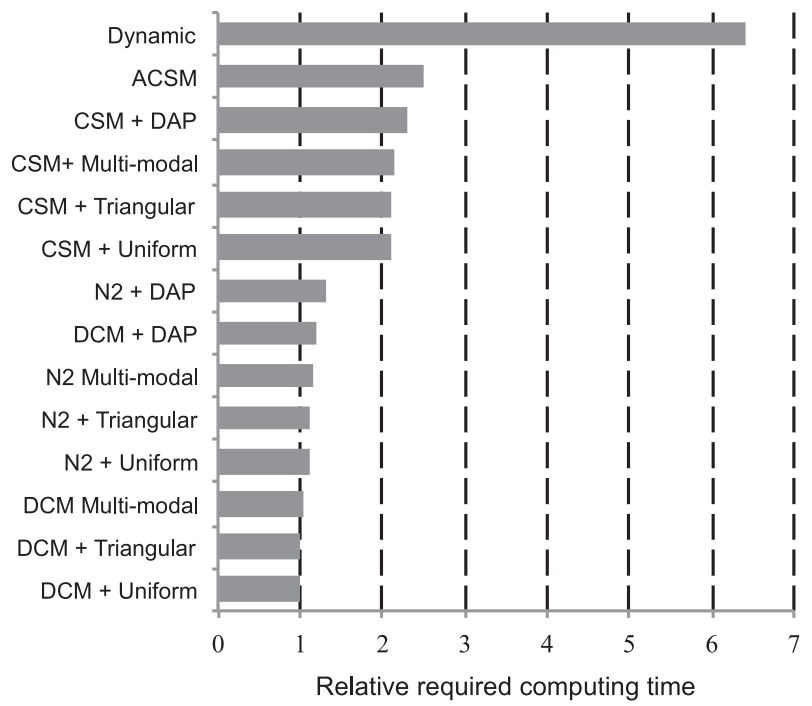

Figure 20. Relative required computational time for each vulnerability methodology. CSM, capacity spectrum method; DCM, displacement coefficient method; ACSM, adaptive capacity spectrum method; N2, N2 method; DAP, displacement based adaptive pushover.

demanding due to the necessary iterative process that often requires several trials for convergence to be achieved. Moreover, carrying out these methodologies in an automatic manner can be very challenging if real accelerograms are employed, mainly because the corresponding response spectra can intersect the capacity curve in many points. Finally, the nonlinear dynamic analysis proved to be the most time consuming, as expected. This last methodology also has the drawback of often presenting convergence problems, thus requiring constant monitoring throughout the analysis.

\section{CONCLUSIONS}

In this study, 13 sets of fragility functions were produced on the basis of many different combinations of pushover curves and nonlinear static procedures, as well as a set of fragility functions by using nonlinear dynamic analysis, totalling more than 140,000 simulations. It is important to establish that any conclusions yielded herein are conditional on the building typology, methodologies, and assumptions followed by the authors, and extrapolation to other cases calls for due care. Extending this study to cover 3D structures and to consider more accurate damage state criteria (such as interstory drift or chord rotations) is the subject of future studies.

Despite the discrepancies in the estimated seismic response of structures when employing different methodologies, as already shown by many authors $[10,12,51]$, it has been concluded in this study that those notable differences are not necessarily propagated into the resulting fragility/vulnerability functions. This decrease in the discrepancies between different methodologies is because the focus is not on the member level performance (in terms of bending moments or shear forces) of an individual structure but rather on the global damage state of the building, which is correlated with the maximum roof displacement. Thus, instead of obtaining differences in the order of 50\% as seen in the target displacement of single structures when employing different methodologies [10], the maximum variation in the results did not exceed $18 \%$ in the vulnerability functions and $14 \%$ in the seismic risk parameters.

Considering the results from nonlinear dynamic analysis as the baseline method, it can be stated that the application of the DCM or the N2 method gave more accurate results than those provided by the CSM. However, as discussed in Section 4.1, improvements to the ATC-40 CSM in the bilinearization process have been proposed but have not been adopted herein (as it was felt that the more common practices should be investigated). It is expected that more accurate results would be attained with the consideration of these improvements. Although very different from a practical 
point of view, the DCM and the $\mathrm{N} 2$ method both use inelastic spectra to estimate the target displacement, which is probably one of the causes of the similarity in the results. Furthermore, the employment of $\mathrm{N} 2$ combined with adaptive pushover curves provided results within $2 \%$ of those attained with the nonlinear dynamic analysis, which shows that a simplified methodology with a much lower computational effort can still provide reliable and accurate results. Regarding the ACSM, which differs from the CSM + DAP configuration in the process to build the bilinear curve, in the damping model, and in the way the equivalent SDOF capacity curve is calculated; also satisfactory results were obtained.

It can be concluded from the results presented herein that the best balance between accuracy and efficiency is obtained for the N2+DAP configuration, providing similar vulnerability functions to those obtained with nonlinear dynamic analysis but at a rate that is almost seven times faster. Such findings are of substantial importance for large-scale initiatives that aim to develop fragility/ vulnerability functions for a large number of building typologies (e.g., the Global Earthquake Model [63]), because post-earthquake damage data may not be available for every region or building type, and consequently, an analytical approach might have to be adopted. Performing dynamic analysis to produce vulnerability functions for all the building types within a given region could soon become computationally unfeasible, but the conclusions of this study suggest that NSPs can be used as a valid alternative for the rapid and accurate assessment of seismic vulnerability.

\section{REFERENCES}

1. Sabetta F, Goretti A, Lucantoni A. Empirical fragility curves from damage surveys and estimated strong ground motion. In The 11th European Conference on Earthquake Engineering, Paris, France, 1998.

2. Rossetto T, Elnashai A. Derivation of vulnerability functions for European-type RC structures based on observational data. Engineering Structures 2003; 25(10):1241-1263.

3. Rota M, Penna A, Strobbia C. Processing Italian damage data to derive typological fragility curves. Soil Dynamics and Earthquake Engineering 2008; 28(10-11):933-947.

4. Singhal A, Kiremidjian S. A method for earthquake motion-damage relationships with application to reinforced concrete frames. NCEER report, State University of New York at Buffalo, U.S.A., 1997.

5. Dumova-Jovanoska E. Fragility curves for RC structures in Skopje region. In The 13th World Conference on Earthquake Engineering, Vancouver, Canada, 2004.

6. Akkar S, Sucuoglu H, Yakut A. Displacement-based fragility functions for low- and mid-rise ordinary concrete buildings. Earthquake Spectra 2005; 21(4):901-927.

7. Erberik MA. Fragility-based assessment of typical mid-rise and low-rise RC buildings in Turkey. Engineering Structures 2007; 30(5):1360-1374.

8. Rossetto T, Elnashai A. A new analytical procedure for the derivation of displacement-based vulnerability curves for populations of RC structures. Engineering Structures 2005; 27(3):397-409.

9. Strasser FO, Bommer JJ, Sesetyan K, Erdik M, Cagnan Z, Irizarry J, Goula X, Lucantoni A, Sabetta F, Bal I, Crowley H, Lindholm C. A comparative study of European earthquake loss estimation tools for an earthquake scenario in Istanbul. Journal of Earthquake Engineering 2008; 12(S2):246-256.

10. Chopra AK, Goel RK. Evaluation of NSP to estimate seismic deformation: SDF systems. Journal of Structural Engineering 2000; 126(4):482-490.

11. Dolsek M, Fajfar P. Simplified non-linear seismic analysis of infilled reinforced concrete frames. Earthquake Engineering and Structural Dynamics 2005; 34(1):49-66.

12. Casarotti C, Monteiro R, Pinho R. Verification of spectral reduction factors for seismic assessment of bridges. Bulletin of the New Zealand Society for Earthquake Engineering 2009; 42(2):111-121.

13. Antoniou S, Pinho R. Advantages and limitations of adaptive and non-adaptive force-based pushover procedures. Journal of Earthquake Engineering 2004; 8(4):497-522.

14. ATC-40. Seismic evaluation and retrofit of concrete buildings. Applied Technology Counci: Redwood City, California, USA, 1996.

15. FEMA-440. Improvement of nonlinear static seismic analysis procedures. Federal Emergency Management Agency, Washington, D.C., U.S.A., 2005.

16. Fajfar P. Capacity spectrum method based on inelastic demand spectra. Earthquake Engineering and Structural Dynamics 1999; 28(9):979-993.

17. Bal I, Crowley H, Pinho R, Gulay, FG. Detailed assessment of structural characteristics of Turkish RC building stock for loss assessment models. Soil Dynamics and Earthquake Engineering 2008; 28:914-932.

18. Shome N, Cornell CA, Bazzurro P, Carballo JE. Earthquakes, records and nonlinear responses. Earthquake Spectra 1998; 14(4):469-500.

19. Bommer JJ, Spence R, Erdik M, Tabuchi S, Aydinoglu N, Booth E, Re DD, Pterken D. Development of an earthquake loss model for Turkish catastrophe insurance. Journal of Seismology 2002; 6:431-446. 
20. Priestley MJN. Displacement-based approaches to rational limit states design of new structures. In The 11th European Conference on Earthquake Engineering, Rotterdam, The Netherlands, 1998.

21. Akyuz S, Uyan M. A study on the concrete steel bars used in Turkey. Technical Journal of the Turkish Assembly of Civil Engineering 1992; 35:497-508.

22. Bal I, Yildiz M. Evaluation of concrete quality of existing buildings in the regional municipalities of Istanbul. Journal of the Turkish Chamber Civil Engineering 2005; 80:10-7.

23. Matlab. Available from: http://www.mathworks.com/ [12 September 2012]

24. OpenSEES. Available from: http://opensees.berkeley.edu/. [28 June 2011]

25. Scott BD, Park R, Priestley MJN. Stress-strain behavior of concrete confined by overlapping hoops at low and high strain rates. ACI Journal Proceedings 1982; 79(1):13-27.

26. Giuffrè A, Pinto PE. Il comportamento del cemento armato per sollecitazioni cicliché di forte intensità. Giornale del Génio Civile 1970.

27. Watson-Lamprey J, Abrahamson N. Selection of ground motion time series and limits on scaling. Soil Dynamics and Earthquake Engineering 2006; 26:477-482.

28. Katsanos EI, Sextos AG, Manolis GD. Selection of earthquake ground motion records: A state-of-the-art review from a structural engineering perspective. Soil Dynamics and Earthquake Engineering 2010; 26:157-169.

29. Jayaram N, Lin T, Baker J. A computationally efficient ground-motion selection algorithm for matching a target response spectrum mean and variance. Earthquake Spectra 2011; 27(3):797-815.

30. Turkish Strong motion database. Available from: http://daphne.deprem.gov.tr:89/2K/daphne_v4.php/ [6 August 2012]

31. European strong motion database. Available from: http://www.isesd.hi.is/ [6 August 2012]

32. PEER strong motion database. Available from: http://peer.berkeley.edu/smcat/ [6 August 2012]

33. Global strong motion database. Available from: http://www.cosmos-eq.org/ [6 August 2012]

34. Kalkan E, Guulkan P, Yilmaz N, Celebi M. Probabilistic seismic hazard mapping of the Marmara region. Report No. 08-01, Earthquake Engineering Research Center, 2008.

35. Baez J I, Miranda E. Amplification factors to estimate inelastic displacement demands for the design of structures in the near field. In The 12th World Conference on Earthquake Engineering, Auckland, New Zealand, 2000.

36. Gulkan P, Sozen MA. Inelastic responses of reinforced concrete structure to earthquake motions. ACI Journal Proceedings 1974; 71(12):604-610.

37. Krawinkler H, Seneviratna G. Pros and cons of a pushover analysis of seismic performance evaluation. Engineering Structures 1998; 20(4-6):452-464.

38. Bracci JM, Kunnath SK, Reinhorn AM. Seismic performance and retrofit evaluation of reinforced concrete structures. Journal of Structural Engineering 1997; 123(1):3-10.

39. Elnashai AS. Advanced inelastic static (pushover) analysis for earthquake applications. Structural Engineering and Mechanics 2001; 12(1):51-69.

40. Antoniou S, Pinho R. Development and verification of a displacement-based adaptive pushover procedure. Journal of Earthquake Engineering 2004; 8(5):643-661.

41. JICA. The study on a disaster prevention/mitigation basic plan in Istanbul including seismic microzonation in the Republic of Turkey. Final Report, Japanese International Cooperation Agency, Japan, 2002.

42. Boğaziçi University in Istanbul, Earthquake risk assessment for Istanbul metropolitan area. Final Report, Kandilli Observatory and Earthquake Research Center, Istanbul, Turkey, 2002.

43. CEN. Eurocode 8: design of structures for earthquake resistance - part 1: general rules, seismic actions and rules for buildings. EN 1998-2, Comité Européen de Normalisation, Brussels, Belgium, 2005.

44. Casarotti C, Pinho R. An adaptive capacity spectrum method for assessment of bridges subjected to earthquake action. Bulletin of Earthquake Engineering 2007; 5(3):377-390.

45. Chopra AK, Goel RK. A modal pushover analysis procedure for estimating seismic demands for buildings. Earthquake Engineering and Structural Dynamics 2002; 31(3):561-582.

46. Kalkan E, Kunnath SK. Adaptive modal combination procedure for nonlinear static analysis of building structures. Journal of Structural Engineering 2006; 132(11):1721-1731.

47. Freeman S, Nicoletti J, Tyrell J. Evaluation of existing buildings for seismic risk - a case study of Puget sound naval shipyard, Bremerton, Washington. In The $1^{\text {st }}$ U.S. National Conference on Earthquake Engineering, Berkley, U.S.A., 1975.

48. Freeman S. Review of the development of the capacity spectrum method. ISET Journal of Earthquake Technology 2004; 41(1):1-13.

49. Monteiro R. Probabilistic seismic assessment of bridges. Ph.D. Dissertation, Univ. of Porto, Porto, Portugal, 2011.

50. FEMA-273. NEHRP guidelines for the seismic rehabilitation of buildings. Federal Emergency Management Agency, Washington, D.C., U.S.A., 1997.

51. Lin YY, Chang KC, Wang YL. Comparison of displacement coefficient method and capacity spectrum method with experimental results of RC columns. Earthquake Engineering and Structural Dynamics 2004; 33:35-48.

52. Priestley, MJN, Calvi GM, Kowalsky MJ. Displacement-based Seismic Design of Structures. IUSS Press: Pavia, Italy, 2007.

53. Bommer JJ, Martínez-Pereira A. The effective duration of earthquake strong motion. Journal of Earthquake Engineering 1999; 3(2):127-172.

54. Papanikolaou V, Elnashai A. Evaluation of conventional and adaptive pushover analysis I: methodology. Journal of Earthquake Engineering 2005; 9(6):923-941. 
55. Pinho R, Marques M, Monteiro R, Casarotti C, Delgado R. Evaluation of nonlinear static procedures in the assessment of building frames. Earthquake Spectra 2013, in press.

56. Bhatt C, Bento E. Comparison of nonlinear static methods for the seismic assessment of plan irregular frame buildings with non seismic details. Journal of Earthquake Engineering 2012; 16(1):15-39.

57. Kappos A, Panagopoulos G, Panagiotopoulos C, Penelis G. A hybrid method for the vulnerability assessment of R/C and URM buildings. Bulletin of Earthquake Engineering 2006; 4(4):391-413.

58. Di Pasquale G, Goretti A. Vulnerabilità funzionale ed economica degli edifici residenziali colpiti dai recenti eventi sismici italiani. In The 10 $0^{\text {th }}$ National Conference "L'ingegneria Sismica in Italia", Potenza-Matera, Italy, 2001.

59. FEMA-443. HAZUS-MH technical manual. Federal Emergency Management Agency, Washington D.C. U.S.A., 2003.

60. BU-ARC. Earthquake risk assessment for Istanbul metropolitan area. Project Report, Boğaziçi University and American Red Cross, Boğaziçi University Publications, Istanbul, Turkey, 2002.

61. Demircioglu MB, Sesetyan K, Durukal E, Erdik M. Assessment of earthquake hazard in Turkey. In The 4th International Conference on Earthquake Geotechnical Engineering, Thessaloniki, Greece, 2007.

62. OpenQuake. Available from: http://openquake.org/ [12 September 2012]

63. Global Earthquake Model. Available from: http://www.globalquakemodel.org/ [12 September 2012] 